\title{
TrkB Signaling Directs the Incorporation of Newly Generated Periglomerular Cells in the Adult Olfactory Bulb
}

\author{
Matteo Bergami, ${ }^{1,2}$ Beatrice Vignoli, ${ }^{2}$ Elisa Motori, ${ }^{3}$ Simone Pifferi, ${ }^{4}$ Emanuela Zuccaro, ${ }^{2}$ Anna Menini, ${ }^{4}$ \\ and Marco Canossa ${ }^{2,5}$ \\ ${ }^{1}$ Physiological-Genomics, Ludwig-Maximilians-University, 80336 Munich, Germany, ${ }^{2}$ Department of Neuroscience and Brain Technologies, Fondazione \\ Istituto Italiano di Tecnologia, 16163 Genova, Italy, ${ }^{3}$ Department of Life Quality Studies-Alma Mater Studiorum, University of Bologna, 40126 Bologna, \\ Italy, ${ }^{4}$ International School for Advanced Studies, 34136 Trieste, Italy, and ${ }^{5}$ European Brain Research Institute, 00143 Rome, Italy
}

In the adult rodent brain, the olfactory bulb (OB) is continuously supplied with new neurons which survival critically depends on their successful integration into pre-existing networks. Yet, the extracellular signals that determine the selection which neurons will be ultimately incorporated into these circuits are largely unknown. Here, we show that immature neurons express the catalytic form of the brain-derived neurotrophic factor receptor TrkB [full-length TrkB (TrkB-FL)] only after their arrival in the OB, at the time when integration commences. To unravel the role of TrkB signaling in newborn neurons, we conditionally ablated TrkB-FL in mice via Cre expression in adult neural stem and progenitor cells. TrkB-deficient neurons displayed a marked impairment in dendritic arborization and spine growth. By selectively manipulating the signaling pathways initiated by TrkB in vivo, we identified the transducers Shc/PI3K to be required for dendritic growth, whereas the activation of phospholipase $\mathrm{C}-\gamma$ was found to be responsible for spine formation. Furthermore, long-term genetic fate mapping revealed that TrkB deletion severely compromised the survival of new dopaminergic neurons, leading to a substantial reduction in the overall number of adult-generated periglomerular cells (PGCs), but not of granule cells (GCs). Surprisingly, this loss of dopaminergic PGCs was mirrored by a corresponding increase in the number of calretinin + PGCs, suggesting that distinct subsets of adult-born PGCs may respond differentially to common extracellular signals. Thus, our results identify TrkB signaling to be essential for balancing the incorporation of defined classes of adult-born PGCs and not GCs, reflecting their different mode of integration in the $\mathrm{OB}$.

\section{Introduction}

The olfactory bulb $(\mathrm{OB})$ of rodents is the target destination of new interneurons that are generated in the subependymal zone (SEZ) of the lateral ventricles throughout adulthood (Lledo et al., 2008). Immature neurons leaving the walls of the ventricle migrate for several days along a scaffold composed by glial cells (Lois et al., 1996) and blood vessels (Snapyan et al., 2009), forming the so-called rostral migratory stream (RMS),

Received 0ct. 11, 2012; revised May 16, 2013; accepted May 21, 2013.

Author contributions: M.B. and M.C. designed research;M.B., B.V., E.M., S.P., and A.M. performed research; M.B., B.V., and E.Z. analyzed data; M.B. wrote the paper.

This research was supported by Ministero dell'Istruzione, dell'Università e della Ricerca, Progetto Limonte, and Fondazione San Paolo (to M.C.). M.B. is supported by a Ludwig-Maximilians-University Excellent Research Fellowship. We thank B. Berninger and M. Götz for critical comments on the manuscript; R. Blum for providing the TrkB-expressing vectors; R. Klein for providing TrkB ${ }^{\text {lox/lox }}$ mice; M. Götz for providing Glast:::CreER ${ }^{\mathrm{T} 2}$ mice; E. Castren and L. Tessarollo for BDNF and TrkB riboprobes; A. Lepier and I. Muehlhahn for help with retroviral production; and $G$. Angiolini for technical assistance.

The authors declare no competing financial interests.

Correspondence should be addressed to either of the following: Dr. Matteo Bergami, Physiological Genomics, LudwigMaximilians-University Munich, Schillerstrasse 46, D-80336 Munich, Germany, E-mail: matteo.bergami@med.unimuenchen.de; or Dr. Marco Canossa, Department of Neuroscience and Brain Technologies, Fondazione Istituto Italiano di Tecnologia, via Morego 30, 16163 Genova, Italy, E-mail: marco.canossa@iit.it.

E. Motori's present address: Max Planck Institute for Biology of Ageing, Department of Mitochondrial Biology, D-50931 Cologne, Germany.

E. Zuccaro's present address: Harvard University, Department of Stem Cell and Regenerative Biology, Cambridge, MA 02138.

DOI:10.1523/JNEUROSCI.4812-12.2013

Copyright $\odot 2013$ the authors $\quad 0270-6474 / 13 / 3311464-15 \$ 15.00 / 0$ before entering the OB. There, they leave the RMS and start to migrate radially before incorporating into the $\mathrm{OB}$ circuitry (Lledo et al., 2006). While the vast majority of new neurons become granule cells (GCs; Carleton et al., 2003), a predefined proportion of them (Merkle et al., 2007) continue to migrate through the mitral layer (ML) and external plexifom layer (EPL) to reach the OB glomeruli, where they become periglomerular cells (PGCs), and finally connect to the pre-existing circuitry (Belluzzi et al., 2003). A key question still open about adult neurogenesis consists in unraveling the molecular mechanisms controlling the selection of those neurons that functionally incorporate into the mature network. In the dentate gyrus (DG) of the hippocampus, where all adult-generated neurons virtually acquire the same identity (van Praag et al., 2002), new granule cells are gradually added to the preexisting population of neurons, finally accounting for $\sim 8-$ $10 \%$ of the total number of cells (Lagace et al., 2007; Ninkovic et al., 2007; Imayoshi et al., 2008). Intriguingly, in the OB the mode of functional incorporation seems to change according to the layer (granular or glomerular) targeted by new arriving neurons: GCs mostly replace pre-existing neurons in the GC layer (GCL), whereas new PGCs become gradually added to previously generated neurons in the glomerular layer (GL; Ninkovic et al., 2007; Imayoshi et al., 2008; Adam and Mizrahi, 2011). We hypothesized that this distinct mode of integration could reflect either the existence of layer-specific microenvi- 
ronments or, alternatively, a cell-type-specific dependence upon ubiquitous extracellular signals.

A key factor secreted in response to neuronal activity is the neurotrophin brain-derived neurotrophic factor (BDNF; Poo, 2001). Interestingly, BDNF is expressed both in the SEZ and within the sites of ultimate integration of newborn neurons in the OB (Bath et al., 2008; Galvão et al., 2008). We have recently shown that BDNF and its high-affinity tyrosine kinase receptor TrkB critically regulate the maturation and synaptic integration of newly generated neurons in the adult DG (Bergami et al., 2008), a finding that potentially implies a similar role for TrkB signaling in neurons integrating in the OB. However, while sharing inputs from both mitral and tufted cells, adult-born neurons are substantially subjected to different inputs depending on whether they are incorporated in the GCL or GL (Shepherd, 2004). While GCs become the target of centrifugal inputs from the olfactory cortex, PGCs also receive inputs from olfactory sensory neurons (OSNs), the latter known to express BDNF (Clevenger et al., 2008; Feron et al., 2008). Given this distinctive innervation of GCs and PGCs, the activity-dependent supply of neurotrophins from the pre-existing network could significantly vary among the GCL and GL, raising the question whether this diversity can contribute to the particular incorporation of one or the other class of adult-generated neurons. Here, we present evidence for a physiological role of full-length TrkB (TrkB-FL) during the stages of newborn neurons integration. By conditionally manipulating the expression of TrkB-FL in adult neural stem cells (NSCs) and their progeny, we show that TrkB signaling regulates the degree of connectivity in integrating neurons, particularly in PGCs, by sculpting their dendritic complexity and spine density. Moreover, deletion of $\operatorname{TrkB}$ compromised the survival of dopaminergic PGCs, indicating a critical role of BDNF signaling in balancing the turnover of adult-born PGCs.

\section{Materials and Methods}

Animals. All animals and experimental procedures were used according to our institutional, Italian, and European Union guidelines. Adult male WT mice (C57BL/6) were obtained from Charles River Laboratories. We generated $\operatorname{TrkB}^{\text {lox/lox}}$-Cre mice by crossing $\mathrm{TrkB}^{\text {lox/lox }}$ mice (provided by Rudiger Klein, Max Planck Institute of Neurobiology, Martinsried, Germany) with Glast::CreER ${ }^{\mathrm{T} 2}$ mice (provided by Magdalena Götz, Helmholtz Center Munich, Neuherberg, Germany) and R26R mice expressing the $\beta$-galactosidase reporter gene.

Viral vectors. We used murine Moloney leukemia virus-based vectors, in which gene expression is driven by the chicken $\beta$-actin promoter (CAG; van Praag et al., 2002), to express the following: GFP, DsRed, Cre-GFP fusion protein, TrkB ${ }^{\mathrm{WT}}, \operatorname{TrkB}^{\mathrm{FFF}}, \mathrm{TrkB}^{\mathrm{Shc}}$, and TrkB ${ }^{\mathrm{PLC}}$ receptors (provided by Robert Blum, Institute for Clinical Neurobiology, University of Würzburg, Würzburg, Germany). The final virus titer was $\sim 5-8 \times 10^{7}$ particles $/ \mu$ l.

Stereotactic surgery. The dorsal skulls of anesthetized $(100 \mathrm{mg} / \mathrm{ml} \mathrm{ket-}$ amine plus $20 \mathrm{mg} / \mathrm{ml}$ xylazine in saline solution) 2- to 3-month-old male mice were exposed, and $0.5 \mu \mathrm{l}$ of retrovirus was injected into each hemisphere (coordinates from bregma: anteroposterior $+0.8 \mathrm{~mm}$, lateral $\pm 1.2 \mathrm{~mm}$, ventral $1.7 \mathrm{~mm}$ ) by using a manual syringe pump (Narishige). Mice were allowed to recover and were housed in standard cages until the day they were killed.

Tamoxifen and BrdU administration. One milligram of tamoxifen (Tx; Sigma) dissolved in corn oil (Sigma) was injected twice a day for 5 consecutive days. For assessing proliferation, $100 \mathrm{mg} / \mathrm{kg}$ 5-bromodeoxyuridine (BrdU; Sigma) was injected intraperitoneally every $2 \mathrm{~h}$ for a total of four times to label the majority of dividing progenitors the day before the mice were killed. For label-retaining experiments, BrdU was administered in drinking water $(1 \mathrm{mg} / \mathrm{ml})$ for a total duration of 3 months before mice were killed.
Immunohistochemistry. Dissected brains were sectioned with a vibroslicer (Campden) for thick sections $(100 \mu \mathrm{m})$. Alternatively, brains were incubated overnight in $30 \%$ sucrose solution (Sigma) before embedding them in Tissue-Tek compound (Sakura) for cryostat sectioning (30-50 $\mu \mathrm{m}$ thick). Slices were rinsed in PBS, treated with $0.5 \%$ Triton X-100 (Sigma) for 5-10 min, blocked with 3\% bovine serum albumin (Sigma) in PBS for $10 \mathrm{~min}$ and incubated overnight free floating (vibratome sections) or on slides (cryostat sections) with the following primary antibodies: rabbit anti-TrkB-FL (1:200; catalog \#sc-12, Santa Cruz Biotechnology), rabbit anti-TrkB-T (1:200; catalog \#sc-119, Santa Cruz Biotechnology), rat anti-BrdU (1:1000; catalog \#ab6326, Abcam), guinea-pig anti-doublecortin (DCX; 1:500; catalog \#AB5910, Millipore), rabbit anti-doublecortin (1:1000; catalog \#ab18723, Abcam), chicken anti- $\beta$ gal (1:1000; catalog \#ab9361, Abcam), rabbit anti$\beta$ gal (1:1000; catalog \#55976, MP Biomedicals), chicken anti-GFP (1:1000; catalog \#A10262, Invitrogen), rabbit anti-GFP (1:1000; catalog \#A11122, Invitrogen), rabbit anti-RFP (1:1000; catalog \#600-401-379, Rockland), mouse anti-calretinin (CR; 1:1000; catalog \#MAB1568, Millipore), rabbit anti-caspase-3 (Casp3) active (1:500; catalog \#G7481, Promega), mouse anti-tyrosine hydroxilase (TH; 1:1000; catalog \#MAB318, Millipore), rabbit anti-calbindin (CB; 1:500; catalog \#ab1778, Millipore), rabbit anti-Tbr2 (Tbox transcription factor; 1:1000; catalog \#MAB1615, Millipore), chicken anti-proBDNF (1:300; catalog \#AB9042, Millipore), rabbit antineurofilament H (1:300; catalog \#AB1989, Millipore), mouse anti-NeuN (1:200; catalog \#MAB377, Millipore). The specificity of anti-TrkB antibodies was assessed in immunostaining experiments prior incubation of samples with relative blocking peptides (for TrkB-FL sc-12, sc-12 peptide; for TrkB sc-119, sc-119 peptide; Santa Cruz Biotechnology). After washing in PBS, slices were then incubated for $2 \mathrm{~h}$ at room temperature with the appropriate Alexa Fluor-conjugated secondary antibodies (Jackson Immunoresearch) diluted in blocking buffer. For BrdU detection, sections were first processed for all other antigens (primary and secondary antibodies), then treated with $2 \mathrm{~N} \mathrm{HCl}$ for $30 \mathrm{~min}$ at $37^{\circ} \mathrm{C}$ followed by $15 \mathrm{~min}$ of $0.1 \mathrm{M}$ tetra-borate buffer, $\mathrm{pH}$ 8.5. After extensive washing, sections were incubated 5 min with DAPI (Invitrogen) and then mounted with Acqua Polymount (Polyscience Inc.).

In situ hybridization. Mice were treated with injections of BrdU ( $100 \mathrm{mg} / \mathrm{kg}$, i.p.; Sigma) twice a day for 3 consecutive days and were killed 21 d later. After brain fixation (PFA 4\% in PBS), in situ hybridization was performed on cryostat sections ( $20 \mu \mathrm{m}$ thick) following standard protocols and using an anti-digoxigenin antibody (1:2000, Roche). Mouse TrkB (Klein et al., 1989) and BDNF (Hofer et al., 1990) digoxigenin-labeled riboprobes were generated by in vitro transcription (transcription kit, catalog \#10999644001, Roche) from plasmids provided by L. Tessarollo (Center for Cancer Research, National Cancer Institute (Frederick, MD) and E. Castren (University of Helsinki, Helskinki, Finland).

Western blot analysis. For assessing the specificity of used anti-TrkB antibodies, HEK-293 cells were grown in DMEM (Sigma) supplemented with $10 \%$ FCS (Sigma) and transfected with $1 \mu \mathrm{g}$ of DNA using Lipofectamine 2000 (Invitrogen). Antibodies specificity was controlled by Western blot analysis on cells transfected with (1) control vector (GFP encoding), (2) HA-tagged (at the N-terminal domain) full-length TrkB cDNA (from mouse, provided by R. Blum, University Hospital of Würzburg, Würzburg, Germany), and (3) rat cDNA for TrkB-T1 (Rose et al., 2003). Forty-eight hours after transfection, cell lysates were collected (0.5\% Triton X-100 and $0.5 \%$ deoxycholate in PBS) and protein extracts were resolved by SDS-PAGE. Signal detection was performed using the ECL detection system (GE Healthcare) after incubation with the following primary antibodies: rabbit anti-TrkB (FL) 1:300 (sc-12, Santa Cruz Biotechnology), rabbit anti-TrkB 1:300 (sc-119, Santa Cruz Biotechnology), mouse anti-HA 1:1000 (MMS-101R, Covance), and mouse anti- $\beta$ actin 1:5000 (A2228, Sigma).

Confocal microscopy and quantitative analysis. Confocal imaging was performed using a laser-scanning motorized confocal system (A1, Nikon) equipped with an Eclipse Ti-E inverted microscope and four laser lines $(405,488,561$, and $638 \mathrm{~nm})$. $Z$-stack series were acquired by using either a $20 \times$ air objective [numerical aperture (NA) 0.75 ; Nikon] or a $40 \times$ oil-immersion objective (NA 1.3; Nikon) and by choosing an interstack interval of $2 \mu \mathrm{m}$ (for the $20 \times$ objective) or $0.5-1 \mu \mathrm{m}$ (for the $40 \times$ objective), respectively. 
Cell counting. For quantifying the number of BrdU+ cells in the SEZ, comparable coronal sections between experimental groups were acquired. ImageJ software (National Institutes of Health) was used to count, stack by stack, BrdU+ nuclei among $\beta$ gal stained nuclei, and cell density was calculated. For quantification of cell migration, an upright fluorescence microscope (Nikon) with a $40 \times$ oil-immersion objective was used to visually quantify the number of reporter single- or double-positive cells with respect to their distribution along the RMS. Radial migration within the OB was quantified on assembled large confocal images (usually $8 \times 8$ fields by using a $20 \times$ objective) of entire OB coronal slices. Based on the DAPI staining, the $\mathrm{OB}$ was subdivided off-line in ImageJ into concentric regions of interest (ROIs) consisting of the RMS, internal GCL (defined as the portion of GCL between the RMS and the external GCL), and external GCL (defined as the portion of GCL covering the area extending from the mitral cell layer to a virtual line positioned $200 \mu \mathrm{m}$ deeper toward the RMS). Reporter + cells were then classified following their distribution between these ROIs. A similar method of quantification was used for calculating the density of $\beta g a l+$ cells in TrkB ${ }^{\mathrm{w} / \mathrm{w}}$-Cre and TrkB ${ }^{\text {lox/lox}}$-Cre mice. In this case, large images of OB sections were acquired, and ROIs corresponding to the GCL and GL were manually drawn slice by slice. ImageJ was then used for counting the number of cells located in these ROIs, and cell density was calculated. The same procedure was applied for quantifying the density of cells positive for specific markers in the GL and for assessing the amount of apoptosis.

Morphometric analysis. Single-labeled neurons were acquired by confocal microscopy ( $z$-series interstack of $0.5 \mu \mathrm{m}$ ) with a $40 \times$ oilimmersion objective (NA 1.3) and 2D projections of the acquisitions were obtained. Reconstruction and measurements of dendrites were obtained by using the neurite tracing software NeuronJ (http://www. imagescience.org/meijering/software/neuronj). Reconstructed traces were then used for Sholl analysis (Ghosh laboratory, http://biology.ucsd. edu/labs/ghosh/software) by establishing a $2 \mu \mathrm{m}$ interval between concentric circles.

Spine density analysis. Second-order branches (considered in their entire length) of the superficial dendritic tree extending into the EPL were selected for quantification in GCs. For PGCs, both first- and secondorder dendrites were considered. Selection of neurons and dendrites was based on the integrity of individual branches and uniform expression of DsRed (assessed by confocal microscopy) between branches of the same neuron and among experimental groups of neurons. Spines were usually imaged by acquiring the selected dendrites by confocal microscopy using a $63 \times$ oil objective (NA 1.3) with a digital zoom of 3 . An interstack of 0.2 $\mu \mathrm{m}$ between focal planes was used for acquisitions, and images were then processed by deconvolution using the Huygens Professional 3.0 software (Scientific Volume Imaging, http://www.svi.nl). The number of spines was counted using ImageJ on deconvolved projections, and spine density was obtained by dividing the number of spines by the length of the dendritic segments.

Electro-olfactogram recordings. Electro-olfactogram recordings were performed as previously described (Franceschini et al., 2009). Briefly, the mouse head was cut sagittally to expose the medial surface of the olfactory turbinates, and recordings were measured at the surface of the olfactory epithelium (OE) in response to odorant stimuli in vapor phase. Each odorant (amylacetate, cineole, and acetophenone; Sigma) was prepared in DMSO at a concentration of $1 \mathrm{M}$. Vapor-phase odorant stimuli were generated by placing $0.9 \mathrm{ml}$ of the odorant solution in a $10 \mathrm{ml}$ glass test tube capped with a rubber stopper. For stimulation, a $100 \mathrm{~ms}$ pulse of the odorant vapor at 8 psi was injected into a continuous stream of humidified air.

Statistical analysis. Statistical analysis was performed using GraphPad Prism software; significance was assessed with the Student's $t$ test for pairs of datasets, while one-way ANOVA and appropriate post hoc tests were used for multiple datasets. Data are expressed as the mean \pm SEM.

\section{Results}

Cell- and region-specific expression of TrkB within the SEZ-RMS-OB system

We first examined the expression pattern of TrkB mRNA and protein in the RMS/OB system of adult mice. In situ hybridiza- tion revealed a widespread expression of TrkB mRNA in the cortex, hippocampus, anterior olfactory nucleus (AON), and $\mathrm{OB}$ (Fig. 1A). Relatively low levels of mRNA were detected in the lateral SEZ (in comparison with other areas; Fig. $1 B$ ), while substantial TrkB mRNA expression was visible at every layer of the OB (Fig. 1C). It is well known that different variants of TrkB receptor are expressed in the CNS (Klein et al., 1989, 1990). We therefore analyzed the protein distribution of the full-length TrkB, which contains the intracellular catalytic domain (TrkBFL), in comparison with that of truncated TrkB (TrkB-T), lacking the catalytic domain (Fig. 1D,E; Minichiello, 2009). To this aim, we used commercially available antibodies recognizing either TrkB-FL or TrkB-T, with prior assessment of their specificity by Western blot (Fig. $1 F$ ). Notably, while TrkB-FL expression was prominent in the $\mathrm{OB}$, particularly in the GCL, ML, and GL (Fig. $1 G)$, TrkB-T expression was almost exclusively confined to the RMS and was virtually absent from the superficial layers of the OB (Fig. 1H).

Given this clear regionalization in the expression of the two main isoforms of TrkB within the RMS/OB system, we sought to investigate whether TrkB plays a role during the migration, maturation, and integration of adult-generated neurons into the $\mathrm{OB}$ network. We thus focused on the expression pattern of this receptor starting from the stage of neuroblast in the SEZ until the acquisition of a mature neuronal morphology and during the process of integration in the OB. To label newly generated neurons, we injected a GFP-encoding retrovirus into the SEZ of 8 -week-old mice (Brill et al., 2009) and analyzed TrkB protein expression in GFP + cells at 5 d postinjection (dpi; Fig. 2A), a time when transduced newborn neurons could be observed both in the SEZ and migrating along the entire RMS (Fig. $2 B-G$ ). We could identify a strong immunoreactivity for TrkB-T in the SEZ of the lateral ventricle, mostly colocalizing with GFAP + fibers and not with GFP+/GFAP - transduced cells (Fig. $2 B, C$ ). In contrast, virtually no immunoreactivity for TrkB-FL was detected within the SEZ (Fig. 2D,E). We then explored the expression of TrkB in the RMS and observed a pattern of immunoreactivity similar to that described in the SEZ: TrkB-T was strongly expressed and mostly confined to GFAP + fibers intermingling with GFP + migrating neurons (Fig. $2 F$ ), while the expression of TrkB-FL was virtually absent (Fig. $2 G$ ). Therefore, neuronal precursors and immature migrating neurons originating from the SEZ are devoid of TrkB expression, while GFAP + cells both in the SEZ and RMS selectively express TrkB-T.

To investigate the expression of TrkB mRNA and protein in differentiated GCs and PGCs, we analyzed OB sections at the time when transduced neurons completed their migration and started to synaptically integrate, at $21 \mathrm{~d}$ after their generation (Belluzzi et al., 2003; Kelsch et al., 2008). TrkB mRNA was detected in BrdUlabeled newborn neurons in the GCL (Fig. $2 H$ ). In contrast to the SEZ and RMS, the pattern of TrkB immunoreactivity in the GCL appeared significantly changed. Indeed, newborn GCs previously labeled by retrovirus injection into the SEZ (Fig. 2A) were still devoid of TrkB-T protein (Fig. $2 I, J$ ), but they expressed significant levels of TrkB-FL (Fig. $2 K, L$ ). Similarly, newborn PGCs expressed TrkB mRNA (Fig. 2M) and were specifically immunoreactive for TrkB-FL (Fig. $2 N-P$ ). Together, these data suggest that newly generated neurons upregulate TrkB-FL only after exiting the RMS and during their process of morphological and synaptic maturation, a time window occurring between the second and third week after their generation. 
A

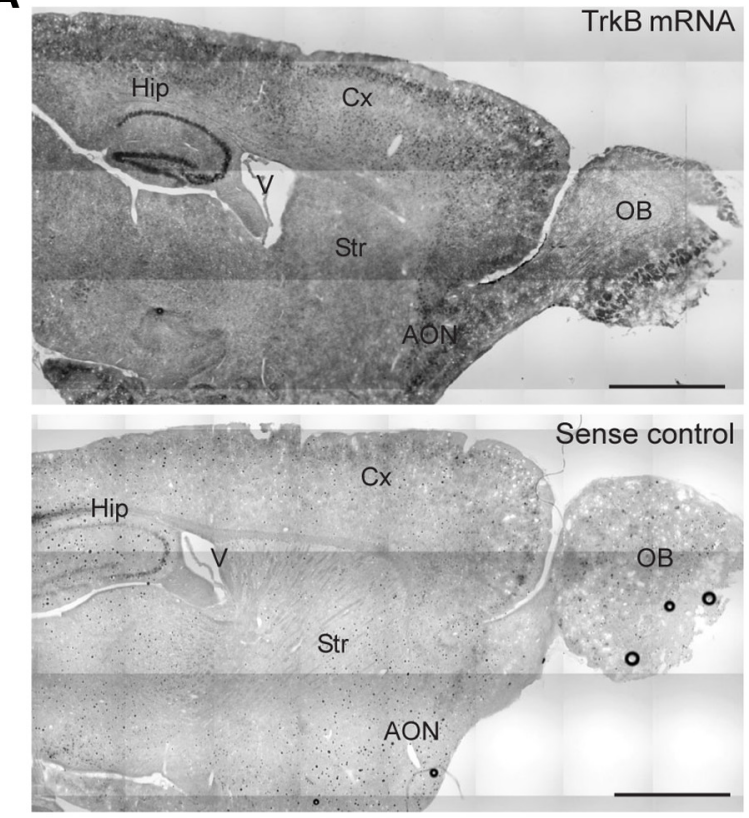

D

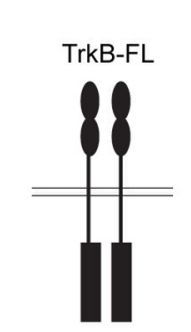

E

$F$

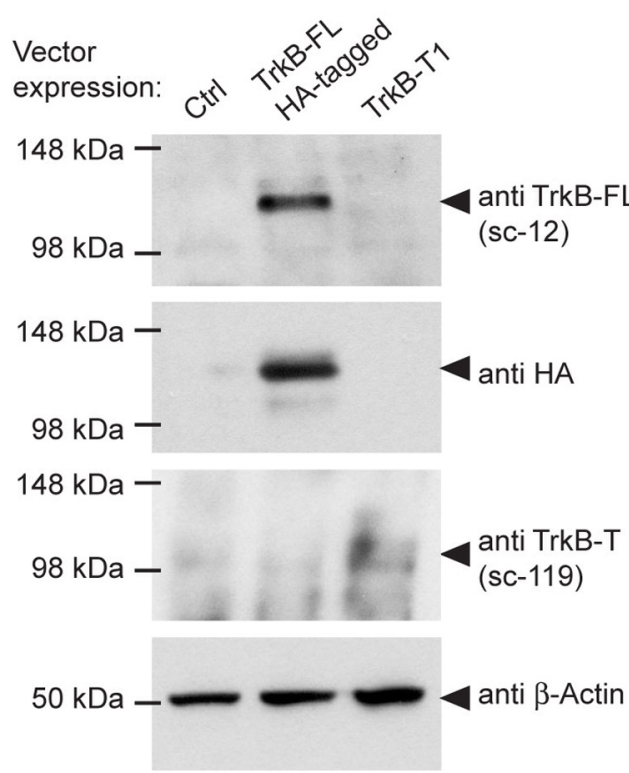

B

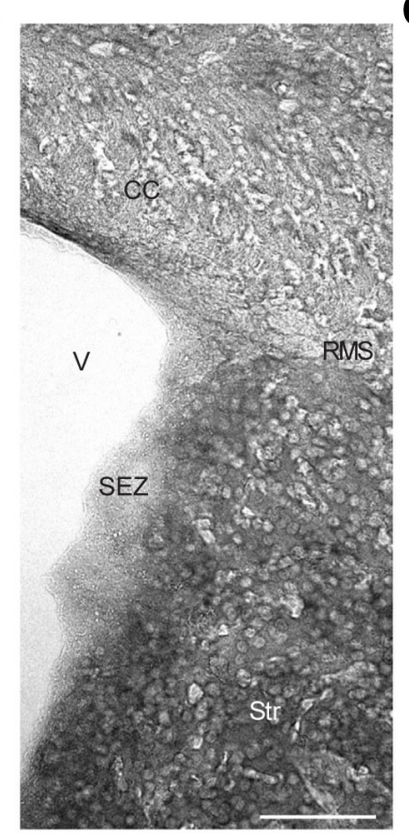

G

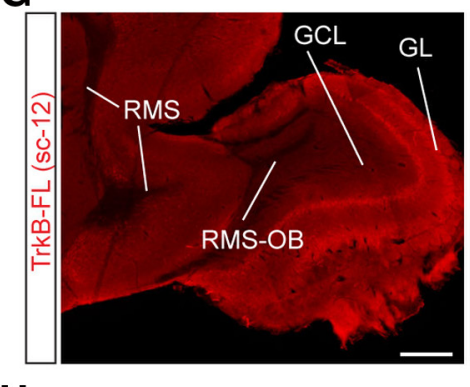

H

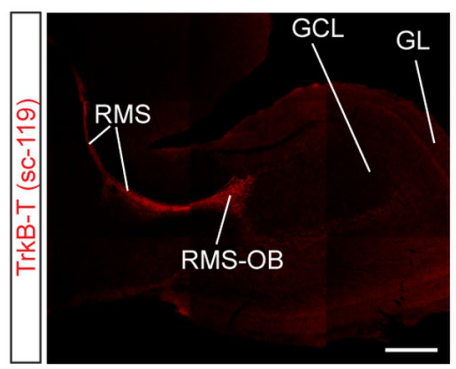

C
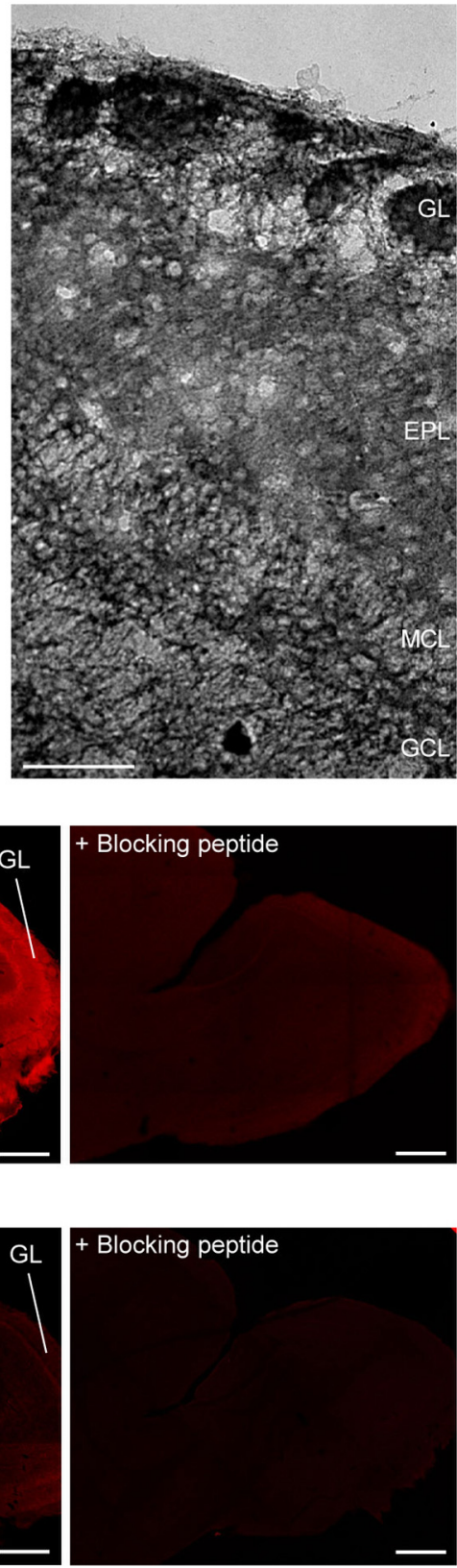

Figure 1. TrkB mRNA and protein distribution in the SEZ/RMS/OB system. $A$, In situ hybridization showing widespread distribution of TrkB mRNA in the adult mouse brain and OB. Scale bars, 1 $\mathrm{mm}$. $\boldsymbol{B}$, High-magnification picture showing TrkB mRNA distribution in the SEZ, RMS, and striatum. Scale bar, $100 \mu \mathrm{m}$. C, High-magnification picture showing TrkB mRNA distribution in the 0B. Scale bar, $100 \mu \mathrm{m} . \boldsymbol{D}$, Schematic showing the structure of the TrkB-FL. $\boldsymbol{E}$, Schematic showing the structure of the TrkB-T lacking the intracellular catalytic domains. $\boldsymbol{F}$, Assessment of the specificity of the used TrkB antibodies by Western blot analysis. HEK-293 cells were alternatively transfected with one of the indicated plasmids: a control vector, a vector encoding for TrkB-FL (HA tagged) or a vector encoding for TrkB-T1. Cell lysates were blotted against TrkB-FL or TrkB-T antibodies or against an HA antibody. G, Immunoreactivity for TrkB-FL in the RMS/OB system assessed with an antibody specifically recognizing the TrkB-FL isoform and validation of the staining by using a specific blocking peptide. Scale bar, $200 \mu \mathrm{m}$. $\boldsymbol{H}$, Immunoreactivity for TrkB-T in the RMS/OB system assessed with an antibody specifically recognizing the TrkB-T isoform and validation of the staining by using a specific blocking peptide. Scale bar, $200 \mu \mathrm{m}$. V, Ventricle; CX, cortex; Hip, hippocampus; AON, anterio olfatory nucleus; $\mathrm{OB}$, olfactory bulb; RMS, rostral migratory stream; SEZ, sub-ependymal zone; $\mathrm{CC}$, corpus callosum; EPL, external plexifom layer; GL, glomerular layer; $M C L$, mitral cell layer; GCL, granule cell layer; Str, striatum.

\section{Deletion of TrkB-FL does not perturb the turnover of} adult-generated GCs in the OB

Given the selective upregulation of TrkB-FL in newborn neurons only upon exiting the RMS, we addressed the question of whether this receptor could have a role in the morphological maturation of GCs and their integration into the OB network. To this aim, we conditionally ablated TrkB-FL in adult SEZ progenitors by crossing Glast::CreER ${ }^{\mathrm{T} 2}$ (Mori et al., 2006) with TrkB ${ }^{\text {lox/lox }}$ mice, in which the second exon of the trkB tyrosine kinase domain is flanked by loxP sites (Minichiello et al., 1999). In the resulting mice, Tx treatment activates the Cre recombinase-ER ${ }^{\mathrm{T} 2}$ fusion protein $\left(C r e R^{\mathrm{T} 2}\right)$ and leads to the selective and permanent deletion of TrkB-FL in the cell lineage originating from Glastexpressing stem and progenitor cells, as well as parenchymal astrocytes (Mori et al., 2006; Ninkovic et al., 2007), leaving the expression of truncated isoforms unaltered (Minichiello et al., 1999; Bergami et al., 2008). To monitor recombined cells and their neuronal progeny over time, we also crossed the resulting 

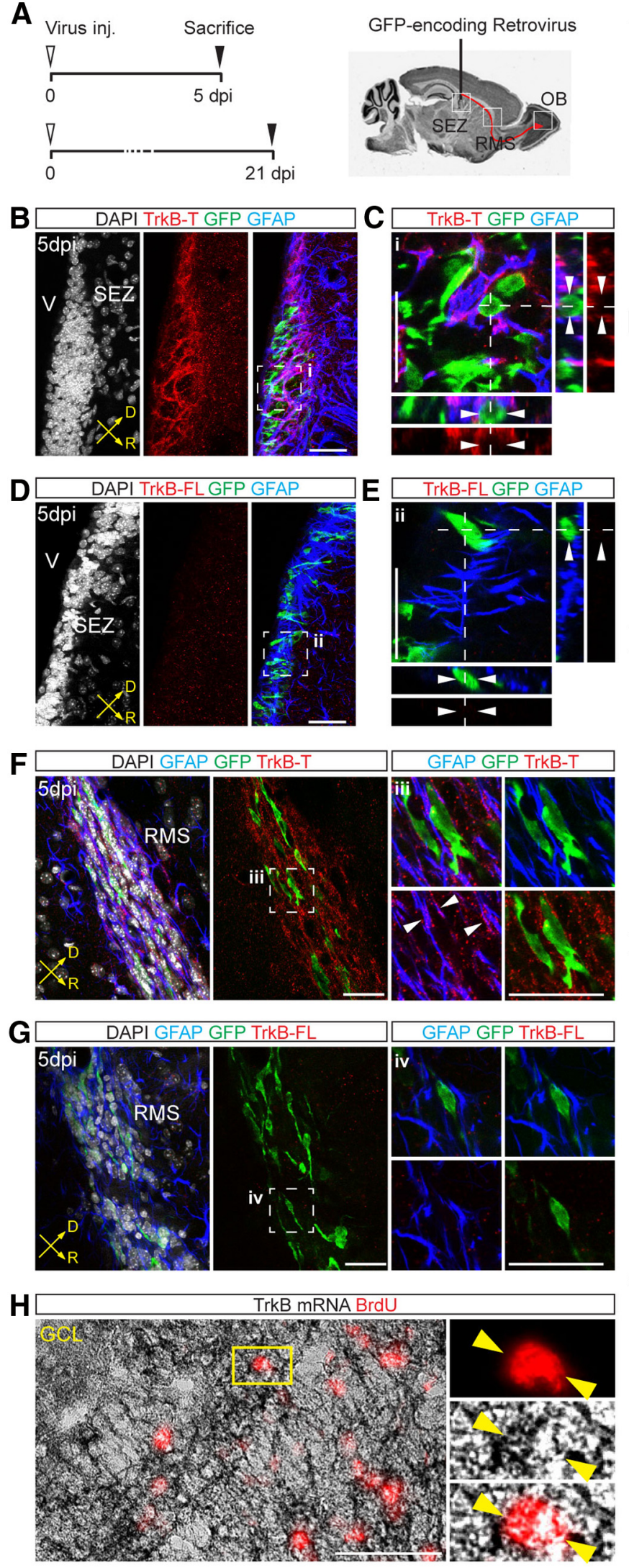

I
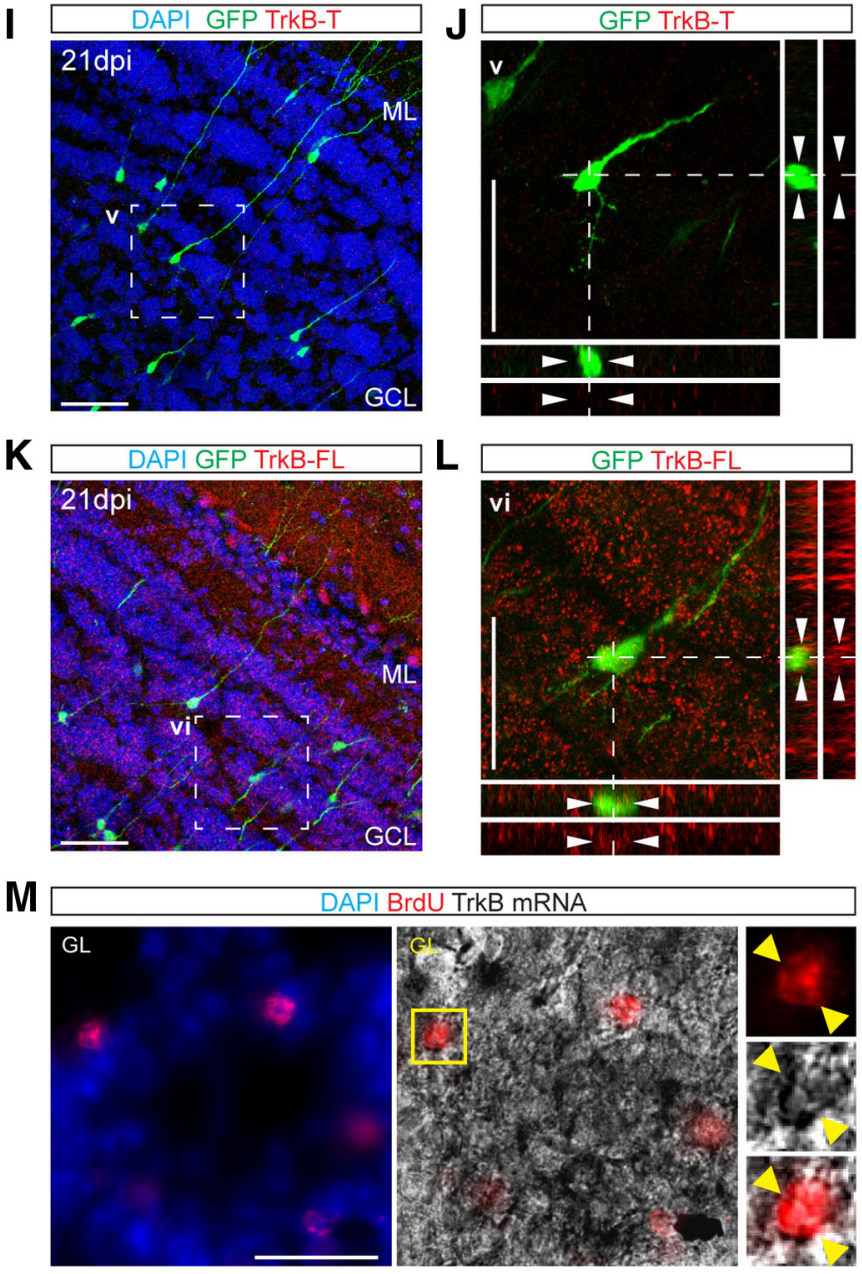

$\mathbf{N}$
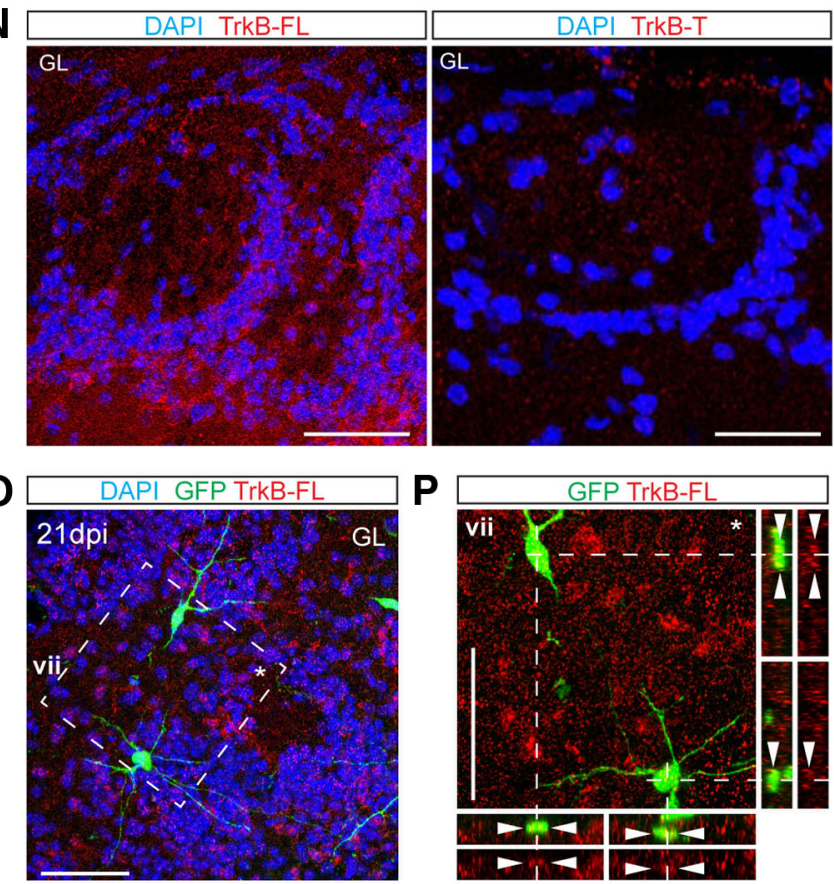

Figure 2. Expression pattern of TrkB in newly generated OB neurons. $A$, Schematic of the experimental protocol used for retroviral labeling of neuronal precursors and newborn neurons in the $S E Z$, RMS, and OB. B, Immunoreactivity for TrkB-T in the SEZ. Injection of a GFP-encoding retrovirus was used to label neuronal precursors at $5 \mathrm{dpi}$. Scale bar, $50 \mu \mathrm{m}$. $\boldsymbol{C}$, Zoom of the area (i) boxed in $\boldsymbol{B}$. Arrowheads in the orthogonal views point to an individual GFP + GFAP - neuronal precursor cell. Scale bar, $50 \mu \mathrm{m}$. $\boldsymbol{D}$, Immunoreactivity for TrkB-FL in the adult SEZ at $5 \mathrm{dpi}$. Scale bar, $50 \mu \mathrm{m}$. $\boldsymbol{E}$, Zoom of the area (ii) boxed in $\boldsymbol{D}$. Scale bar, $50 \mu \mathrm{m}$. $\boldsymbol{F}$, View of the RMS at 5 dpi showing the absence of TrkB-T immunoreactivity in GFP + migrating neurons. Right panels show enlargement (single stacks) of the boxed area (iii) pointing to a colocalizing signal (arrowheads) between TrkB-T and GFAP + fibers. Scale bar, $50 \mu \mathrm{m}$. G, Pictures showing the (Figure legend continues.) 
mouse line with ROSA26 (R26R) reporter mice, in which the Rosa26 locus encodes the expression of $\beta$ gal following Cremediated recombination (Soriano, 1999). In these mice (hereafter referred as to $\mathrm{TrkB}^{\mathrm{w} / \mathrm{w}}$-Cre and TrkB ${ }^{\text {lox/lox}}$-Cre mice), the majority $(>80 \%)$ of newly generated neuronal precursors, identified by the marker DCX, express $\beta$ gal in the SEZ and proximal RMS (Fig. $3 A, B$ ), confirming the high rate of recombination (Ninkovic et al., 2007). Also, as shown for wild-type mice (Fig. 2), no expression of TrkB-FL was observed in $\beta$ gal $+/ \mathrm{DCX}+$ cells in the SEZ/RMS (Fig. 3B). Consistent with the lack of TrkB-FL expression in the SEZ, the rate of proliferation as evaluated by BrdU incorporation at $14 \mathrm{~d}$ post-Tx treatment (dptx) did not change between $\operatorname{TrkB}^{\mathrm{w} / \mathrm{w}}-$ Cre and $\operatorname{TrkB}^{\text {lox/lox }}$-Cre mice (Fig. $3 C-E$ ), indicating that deletion of TrkB-FL did not perturb the proliferative steps of neurogenesis.

We further examined any cell-autonomous contribution of TrkB-FL in the migration of newly generated neurons along the RMS and through the GCL of the OB. Although no TrkB-FL immunoreactivity was observed in migrating neurons (Fig. $2 G$ ), TrkB-FL expression could be present at levels below the detectability threshold of this method. Therefore, TrkB ${ }^{\text {lox/lox }}$ mice were injected with a CreGFP-expressing retrovirus together with a DsRed-only-encoding virus, and neurons that were single or double transduced were compared for their capability to properly migrate along the RMS (Fig. $3 F$ ). We first performed a time course analysis at early time points $(3,5$, and $7 \mathrm{dpi})$ after viral transduction by examining the distribution of transduced neurons throughout the SEZ and both proximal and distal parts of the RMS (Fig. 3G). In agreement with previous studies (Galvão et al., 2008; Snapyan et al., 2009), we found no overt changes in the migration of newborn neurons lacking TrkB-FL compared with controls at any of the analyzed time points (Fig. $3 H$ ). Likewise, analysis of control and TrkB-deficient neurons at $12 \mathrm{dpi}$, the time when they reached the edge of the GCL (Fig. $3 I, J$ ), revealed no differences in their relative distribution within the OB (Fig. $3 K$ ), indicating that both chain migration through the RMS and radial migration through the GCL were not significantly affected by TrkB-FL deletion in adult-generated neurons.

Previous studies have investigated the contribution of adultgenerated neurons to the maintenance of the existing $\mathrm{OB}$ network depicting a scenario in which new GCs constantly replace pre-existing GCs within the GCL (Ninkovic et al., 2007; Imayoshi et al., 2008). To address the question of whether TrkB-FL could have a role for the proper integration/replacement of GCs, we first compared the morphological development of new GCs between $\operatorname{TrkB}{ }^{\mathrm{w} / \mathrm{w}}$-Cre and $\operatorname{TrkB}{ }^{\text {lox/lox }}$-Cre mice. A substantial reduction in the expression levels of TrkB-FL was observed in

\footnotetext{
(Figure legend continued.) immunoreactivity for TrkB-FL in the RMS at 5 dpi. Right panels show enlargement (single stacks) of the boxed area (iv). Scale bar, $50 \mu \mathrm{m}$. $\boldsymbol{H}$, In situ hybridization performed following BrdU label-retaining experiments (animals were analyzed at 3 weeks after BrdU treatment) showing the distribution of TrkB mRNA in adult-born GCs of the OB. High magnification images on the right show TrkB mRNA in an individual $B r d U+$ newborn $\mathrm{GC}$ in the GCL. Scale bar, $50 \mu \mathrm{m}$. I, Expression of TrkB-T in GCs at 21 dpi. Scale bar, $50 \mu \mathrm{m} . J$, Enlargement of the area (v) boxed in I showing lack of TrkB-T expression. Scale bar, $50 \mu \mathrm{m} . \boldsymbol{K}$, Expression of TrkB-FL in GCs at 21 dpi. Scale bar, $50 \mu \mathrm{m}$. $\boldsymbol{L}$, Enlargement of the area (v) boxed in $\boldsymbol{K}$. Scale bar, $50 \mu \mathrm{m} . \boldsymbol{M}$, Analysis of TrkB mRNA in adult-born PGCs labeled with BrdU. High magnification images on the right show TrkB mRNA in an individual BrdU + newborn PGC. Scale bar, $50 \mu \mathrm{m}$. $\boldsymbol{N}$, Expression pattern of TrkB-FL (left) and TrkB-T (right) in the GL. Scale bar, $50 \mu \mathrm{m} . \mathbf{0}$, Expression of TrkB-FL in adult-born PGCs at $21 \mathrm{dpi}$. Scale bar, $50 \mu \mathrm{m}$. $\boldsymbol{P}$, Enlargement of the area (vi) boxed in $\mathbf{O}$ showing colocalization between GFP+ PGCs and TrkB-FL. Scale bar, $50 \mu \mathrm{m}$. V, Ventricle; D, dorsal; $R$, rostral; inj., injection.
}

$\beta$ gal + neurons exiting the RMS of TrkB ${ }^{\text {lox/lox }}$-Cre mice by 21 dptx, demonstrating the loss of TrkB-FL in these cells upon recombination (Fig. 4A). To monitor the extension of dendritic branches and protrusions in these cells, we injected a DsRedencoding retrovirus into the SEZ of Tx-treated $\operatorname{TrkB}^{\mathrm{w} / \mathrm{w}}$-Cre and TrkB ${ }^{\text {lox/lox }}$-Cre mice, and analyzed the morphological features of labeled neurons in the GCL at $21 \mathrm{dpi}$ (Fig. 4B), a time point mirroring the acquisition of morpho-functional hallmarks in newly generated GCs (Whitman and Greer, 2007; Nissant et al., 2009). Sholl analysis (Sholl, 1953) revealed that the dendritic tree of TrkB-deficient neurons was not significantly altered compared with control neurons, both in terms of branching and total length (Fig. 4B-D). However, neurons lacking TrkB-FL displayed a significant reduction in the spine density of superficial dendrites located in the EPL (Fig. $4 B, E$ ). To assess for the specificity of this phenotype, we analyzed whether and how these morphological properties could be influenced by the different signaling pathways activated by TrkB-FL. Therefore, we injected Tx-treated $\mathrm{TrkB}^{\text {lox/lox}}$-Cre mice with retroviruses encoding for specific isoforms of the TrkB receptor including the wild-type (TrkB ${ }^{\mathrm{WT}}$, for rescuing experiments) and the catalytically inactive form of TrkB-FL (TrkB ${ }^{\mathrm{FFF}}$, mutated in the autophosphorylation site) and two isoforms selectively mutated in either (1) tyrosine 515 of the catalytic domain, which mediates the activation of the PI3K signaling pathway by interacting with the docking molecule Shc (Minichiello, 2009; $\operatorname{TrkB}^{\text {Shc }}$ ); or (2) tyrosine 816 , which is responsible for the induction of phospholipase C- $\gamma$ (PLC $\gamma)$ signal-

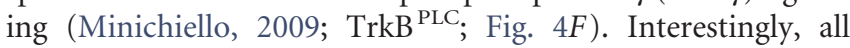
isoforms lead to no significant changes in the extent of dendritic arborization of newborn neurons (Fig. 4C,D). However, while TrkB ${ }^{\mathrm{WT}}$ could rescue spine density in TrkB knock-out adultborn GCs, neurons transduced with $\operatorname{TrkB}^{\mathrm{FFF}}$ and $\operatorname{TrkB}^{\mathrm{PLC}}$ retroviruses displayed a reduction in spine growth similar to that observed in DsRed-only transduced neurons in TrkB ${ }^{\text {lox/lox }}$-Cre mice (Fig. 4E), suggesting that disruption of TrkB-mediated PLC $\gamma$ signaling specifically affected spine growth in newborn GCs.

Based on these results, we tested the hypothesis of whether a reduction in spine density, suggestive of impaired integration, would affect the incorporation rate or turnover of newborn neurons in the GCL. We designed an experimental plan aimed at highlighting differences in the survival and turnover of neurons generated during adulthood and during aging. TrkB ${ }^{\text {lox/lox}}-$ Cre mice and control littermates were treated with Tx at 2 months of age and were analyzed at different points along a time course lasting 9 months (Fig. 4G). As previously reported (Lagace et al., 2007; Ninkovic et al., 2007; Imayoshi et al., 2008), control mice displayed a gradual increase in the total number of reporter+ GCs during the first 3 months post-Tx treatment (mptx), after which a plateau was reached (Fig. $4 H, I$ ). Unexpectedly, we could observe the same number of reporter+ GCs at all investigated time points in either the presence or absence of TrkB-FL (Fig. $4 H, I)$, suggesting that interfering with TrkB signaling did not affect either the short-term or the long-term survival of adultborn GCs. Next, we investigated whether TrkB-FL could have a function in maintaining the correct self-replacement of adultgenerated GCs (Imayoshi et al., 2008) and addressed the contribution of distinct temporal phases of neurogenesis to the total pool of this population of cells in TrkB mutant mice. We treated the last two groups of animals (killed at 6 and $9 \mathrm{mptx}$ ) with BrdU during their last 3 months of life (Fig. 4G) to selectively label GCs generated within these time windows, and analyzed the corresponding proportion of single-labeled $(\beta \mathrm{gal}+/ \mathrm{BrdU}-)$ versus 

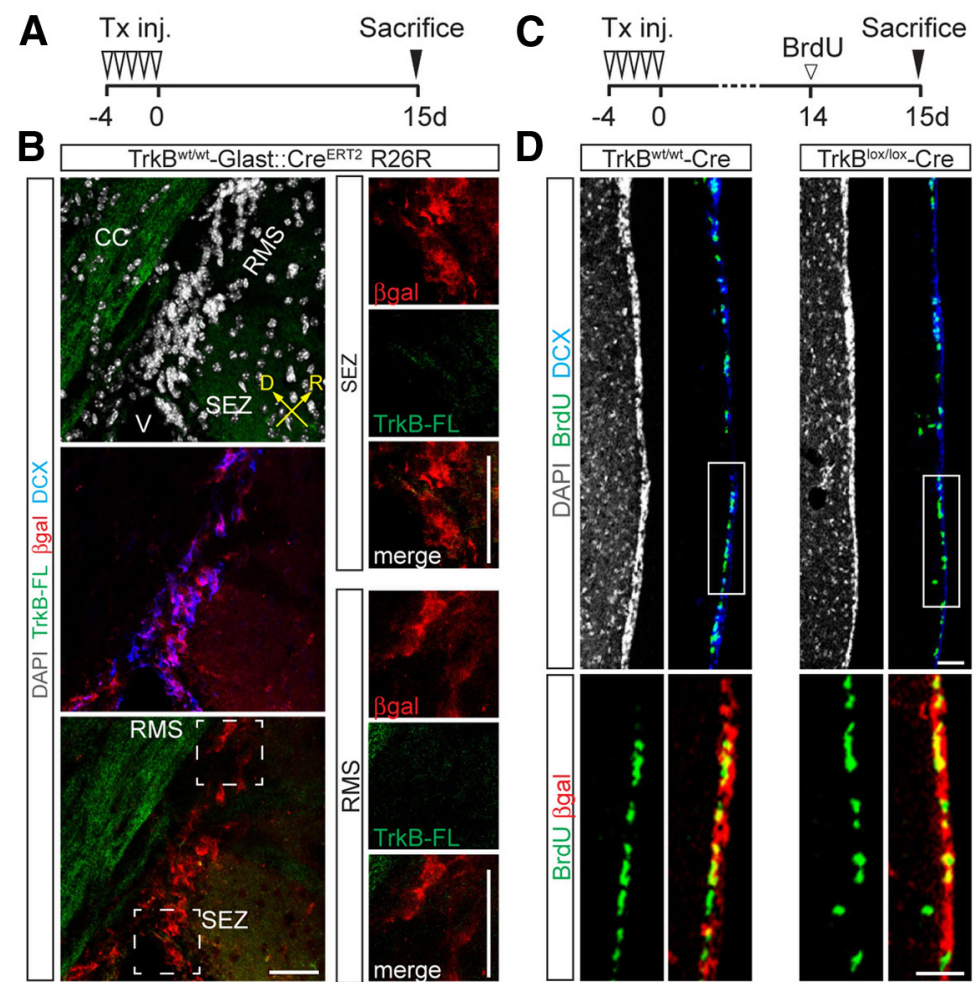

E

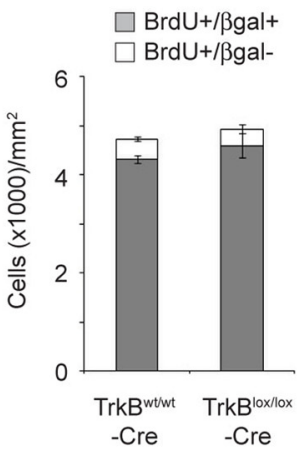

G
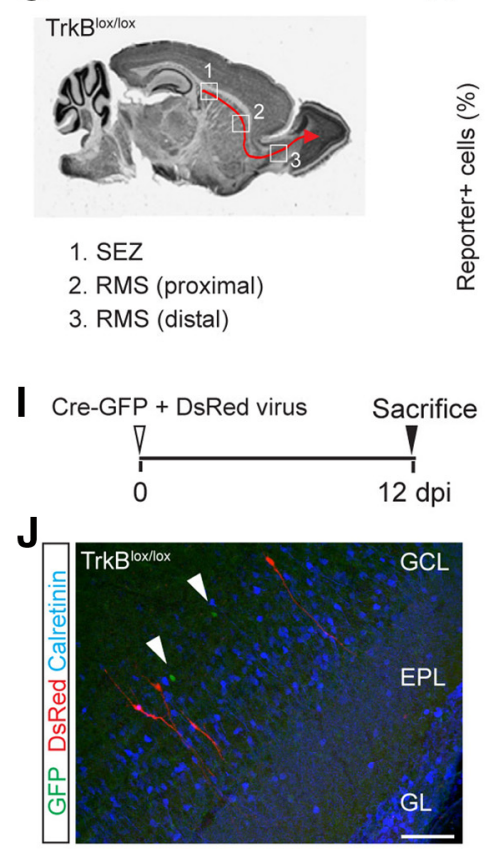

F Cre-GFP virus + DsRed virus
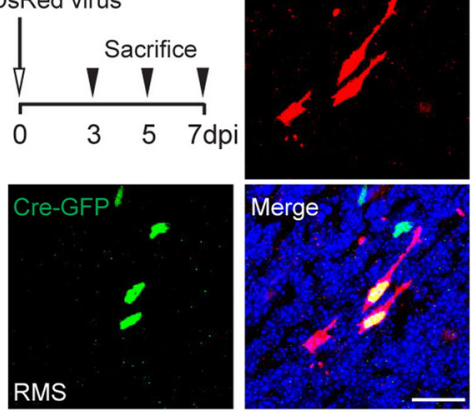

H
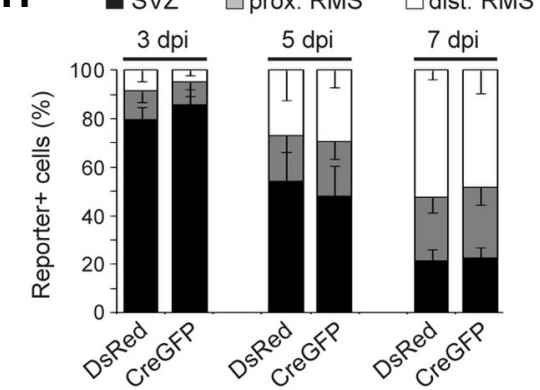

K

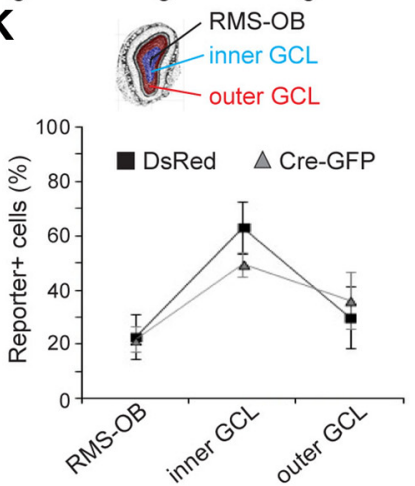

double-labeled cells $(\beta g a l+/ B r d U+$; Fig. $4 J)$. Consistent with a general reduction in neurogenesis with aging, the number of $\beta \mathrm{gal}+/ \mathrm{BrdU}+$ cells generated in control mice during the period 6-9 mptx was substantially lower compared with the number of cells generated between 3 and 6 mptx (Fig. 4K). Strikingly, we found no differences in the relative densities of $\beta g a l+$ cells between $\operatorname{TrkB}^{\mathrm{w} / \mathrm{w}}$-Cre and TrkB ${ }^{\text {lox/lox }}$-Cre mice, which both showed similar numbers of GCs being integrated during the preceding 3 months of life $(\beta \mathrm{gal}+/ \mathrm{BrdU}+)$ or before the onset of BrdU treatment (Fig. 4K).

TrkB-FL is required for the morphological maturation and turnover of newly generated PGCs A minor proportion of adult-generated neurons populates the GL of the $\mathrm{OB}$ (Lledo et al., 2008). However, neuronal turnover in this layer follows different dynamics compared with the GCL (Nink-

\section{$\leftarrow$}

Figure 3. Genetic deletion of TrkB-FL does not alter proliferation of NSCs in the SEZ and migration of immature neurons to the $O B$. $A$, Experimental protocol used for Tx induction of TrkB $^{\mathrm{w} / \mathrm{w}}$-Cre mice. $B$, Overview of the SEZ and initial part of the RMS showing the distribution of TrkB-FL and $\beta$ gal + cells in TrkB ${ }^{w / w}$-Cre mice $15 \mathrm{dptx}$. Note the absence of TrkB-FL immunoreactivity in the SEZ and RMS. Right panels show enlargements of the boxed areas (SEZ and RMS). Scale bar, 50 $\mu \mathrm{m}$. C, Experimental protocol used for evaluating cell proliferation in the SEZ. Mice were treated with Tx for $5 \mathrm{~d}$, killed at 15 $d p t x$, and treated with BrdU the day before being killed. $D$, Confocal pictures showing the distribution of BrdU + cells in the SEZ of Tx-treated TrkB ${ }^{w / w}$ and TrkB ${ }^{\text {lox/lox }}$-Cre mice at 15 $d p t x$. Bottom panels show magnifications corresponding to the boxed areas. Scale bar, $50 \mu \mathrm{m}$. E, Quantification of $\beta \mathrm{gal}+$ and $\beta$ gal - cells among BrdU + cells in the SEZ of control and TrkB mutant mice ( $n=3$ mice). $\boldsymbol{F}$, Experimental paradigm (left) used for evaluating the tangential migration of adultborn neurons. TrkB ${ }^{\text {lox/lox }}$ mice were analyzed at 3, 5, and $7 \mathrm{dpi}$ following coinjection of a retrovirus encoding for Cre-GFP (fusion protein) together with DsRed-encoding virus. Pictures show single- and double-transduced neurons migrating along the RMS after coinjection of Cre-GFP and DsRed retroviruses. Scale bar, $20 \mu \mathrm{m}$. G, Schematic illustrating the subdivision of newborn neuron's migration pathway in three different regions $(1,2,3)$ used for quantifying the distribution of transduced cells in TrkB ${ }^{\text {lox/lox }}$ mice following stereotactic injection into the SEZ. H, Distribution of CreGFP-expressing cells (TrkB knock-out cells) and DsRed-only-expressing cells (controls) at 3 ( $n=3$ mice, 470 cells), 5 ( $n=3$ mice, 280 cells), and $7 \mathrm{dpi}$ ( $n=3$ mice, 752 cells). $I$, Experimental design used for evaluating the radial migration of newborn neurons in TrkB ${ }^{\text {lox/lox }}$ mice. Mice were coinjected with Cre-GFP and DsRed retroviruses and analyzed at $12 \mathrm{dpi}$.J, Picture showing Cre-GFP transduced cells (arrowheads) and DsRed transduced cells located in the GCL at 12 dpi. Scale bar, $50 \mu \mathrm{m}$. $\boldsymbol{K}$, Graph showing the distribution of transduced cells at 12 dpi within the $\mathrm{OB}$. For quantification, the $\mathrm{OB}$ was subdivided in regions corresponding to the RMS-OB, inner and outer $\mathrm{GCL}$ ( $n=4$ mice, 843 cells). $V$, Ventricle; D, dorsal; R, rostral. 

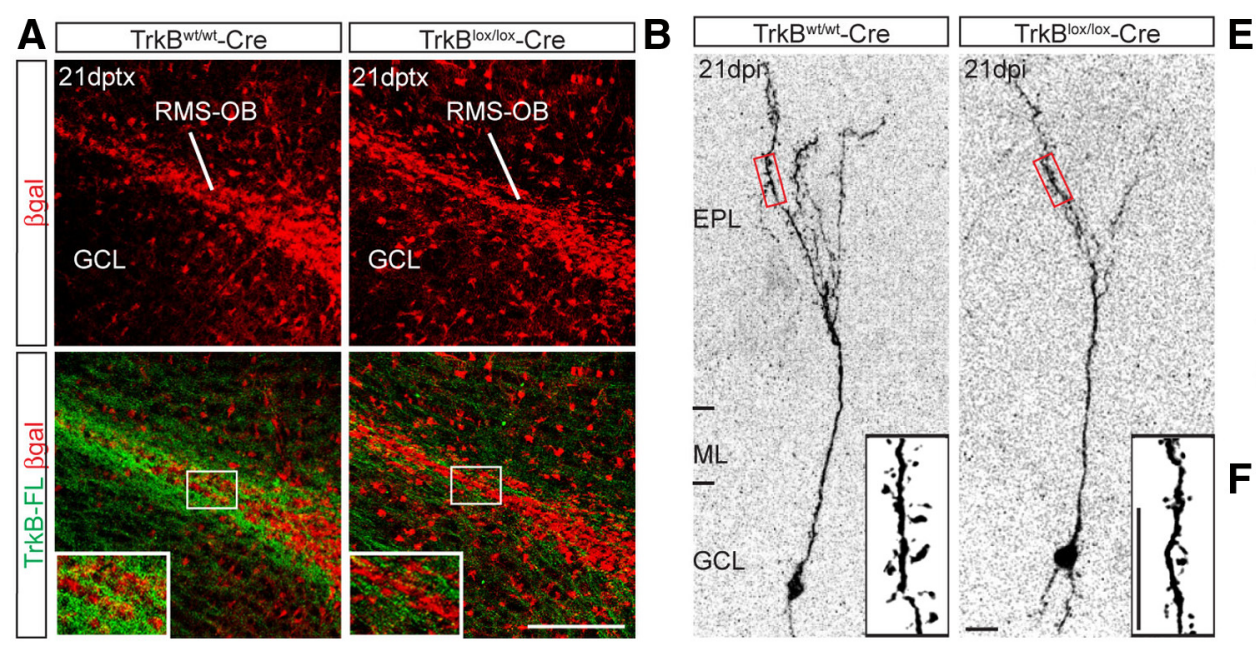

C
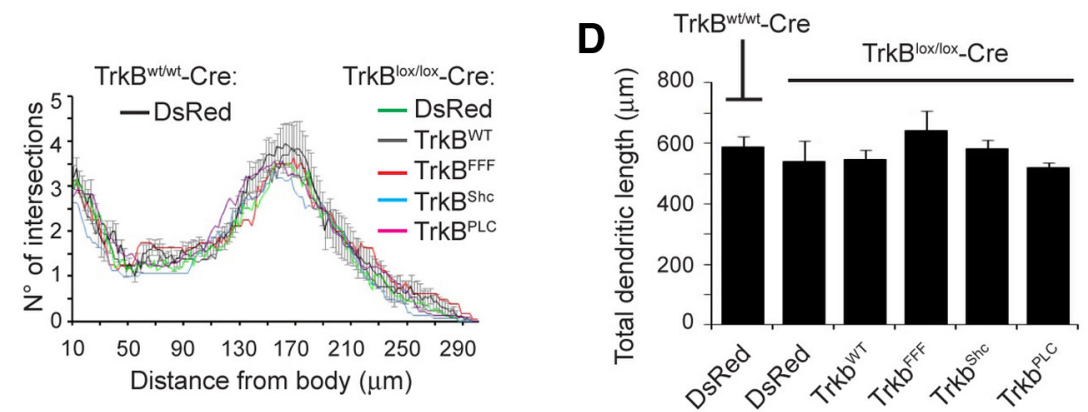

E

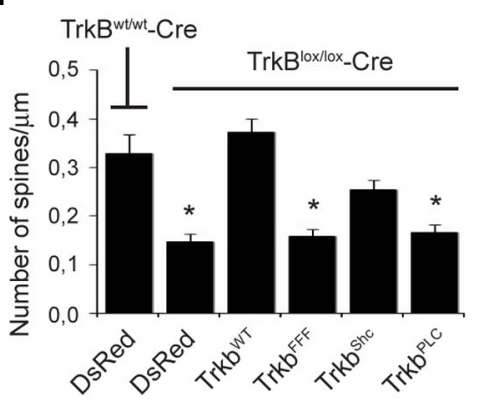

$\mathbf{F}$

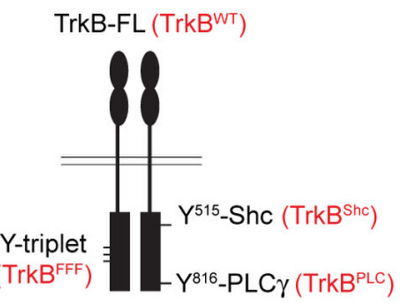

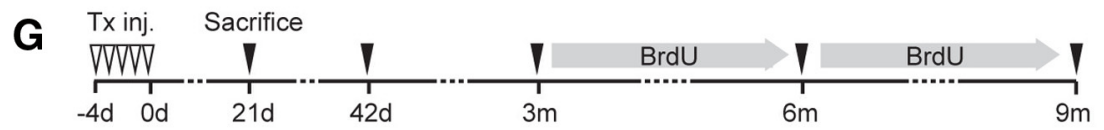
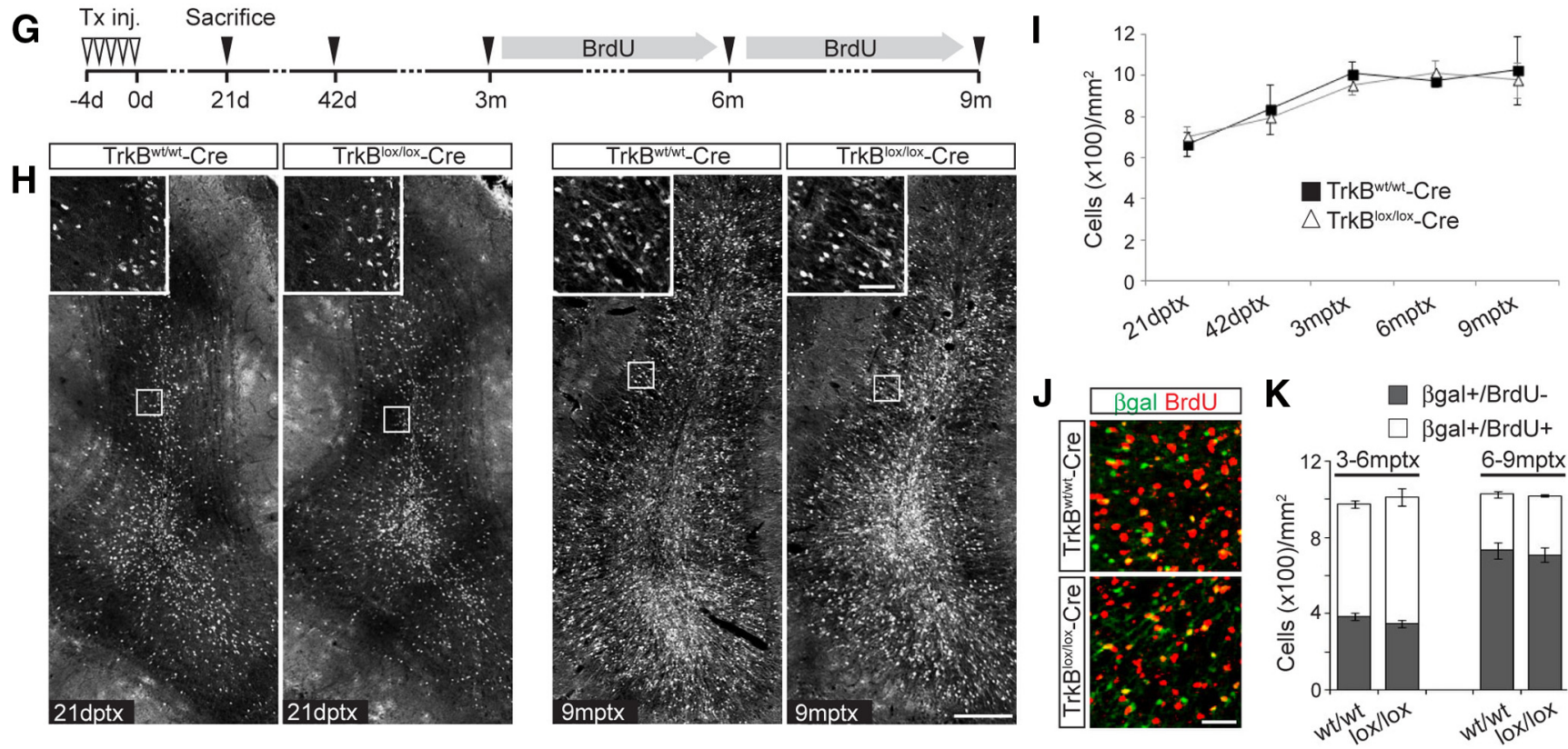

Figure 4. TrkB-FL deletion in newborn GCs impairs spine growth but does not alter neuronal turnover. $A$, Pictures of the $O B$ core region depicting the distribution of $\beta$ gal + neurons and the expression of TrkB-FL in TrkB ${ }^{\mathrm{W} / \mathrm{w}}$-Cre and TrkB ${ }^{\text {lox/lox }}$-Cre mice at $21 \mathrm{dptx}$. Scale bar, $100 \mu \mathrm{m}$. B, Pictures showing the dendritic arborization of DsRed + transduced newborn GCs in Tx-treated TrkB ${ }^{\mathrm{w} / \mathrm{w}}$-Cre and TrkB ${ }^{\text {lox/lox }}$-Cre mice at $21 \mathrm{dpi}$. Insets show high magnification images of spines present along second-order superficial dendrites located in the EPL (boxed areas). Scale bar, $10 \mu \mathrm{m}$. C, Sholl analysis of GCs at $21 \mathrm{~d}$ following transduction with the indicated viral vectors either in Tx-treated TrkB ${ }^{w / w}-$ Cre or TrkB ${ }^{\text {lox/lox }}$-Cre mice $(n=10-15$ neurons/condition). D, Histogram showing the total dendritic length of the newborn $\mathrm{GCS}$ analyzed in $\boldsymbol{C}(n=10-15$ neurons/condition). $\boldsymbol{E}$, Spine density of the neurons analyzed in C. Quantification was performed along second-order dendritic segments located in the EPL ( $n=10-15$ neurons/ condition; two dendritic segments/neuron). ${ }^{*} p<0.05$. F, Schematic showing the TrkB full-length receptor (TrkB ${ }^{\mathrm{WT}}$ ) with indication of the tyrosines $(\mathrm{Y})$, which were mutated into phenylalanines to obtain the following TrkB mutants: (1) a TrkB mutated in the Y-triplet required for auto-phosporilation (TrkB FFF); (2) a TrkB isoform selectively mutated in the tyrosine 515 responsible for initiating the Shc/PI3K pathway $\left(\right.$ TrkB Sh) ${ }^{\text {; }}$ and (3) a TrkB mutated in the tyrosine 816, responsible for initiating the PLC $\gamma$ pathway (TrkB PLC). On the bottom are shown the different DsRed-expressing retroviral constructs encoding for the indicated TrkB isoforms. G, Experimental plan designed for assessing the long-term turnover of adult-generated GCs. Mice were treated with Tx and analyzed at $21 \mathrm{dptx}, 42 \mathrm{dptx}, 3 \mathrm{mptx}, 6 \mathrm{mptx}$, and $9 \mathrm{mptx}$. Mice

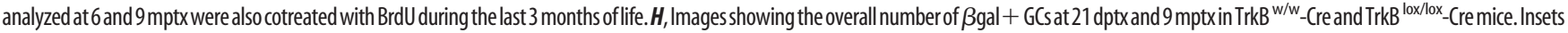
show high magnification images of the boxed areas. Scale bars: $\boldsymbol{H}, 200 \mu \mathrm{m} ; \boldsymbol{H}$, inset, $50 \mu \mathrm{m}$. I, Quantification of $\beta \mathrm{gal}+\mathrm{GCs}$ for each indicated time point $(n=3 \mathrm{mice})$. J, Density of $\beta \mathrm{gal}+/ \mathrm{BrdU}-$ and double-positive cells in a representative area of the $\mathrm{GCL}$ at $6 \mathrm{mptx}$ in TrkB ${ }^{\mathrm{w} / \mathrm{w}}$-Cre and TrkB ${ }^{\text {lox/lox}}$-Cre mice following BrdU treatment as indicated in $\boldsymbol{G}(n=3$ mice). Scale bar, $30 \mu \mathrm{m}$. $\boldsymbol{K}$, Density of BrdU + and BrdU - GCs among the total number of $\beta g a l+G C s$ at 6 and $9 \mathrm{mptx}$ ( $n=3$ mice). 
ovic et al., 2007; Adam and Mizrahi, 2011). The distribution of TrkB-FL protein in this region was found to be largely confined to the borders of glomeruli where the majority of newborn PGCs integrate (Fig. $2 N$ ). Single-cell analysis of Tx-induced TrkB ${ }^{\text {lox/ }}$ lox-Cre mice confirmed the loss of TrkB-FL expression from $\beta$ gal + PGCs (Fig. 5A).

We examined the density of reporter + cells within the GL during a time course ranging from $21 \mathrm{dptx}$ to $9 \mathrm{mptx}$, as described before for the GCL (Fig. 4G). The total number of PGCs in control mice increased over time without reaching any visible plateau (Fig. $5 B, C$ ), suggesting a model in which the majority of supplied neurons are continuously added to pre-existing adult-generated neurons (Ninkovic et al., 2007; Adam and Mizrahi, 2011). Interestingly, we could detect a significant reduction in the density of $\beta$ gal + PGCs in TrkB ${ }^{\text {lox/lox}}$-Cre mice compared with control littermates at $21 \mathrm{dptx}(37.6 \pm 7.6 \%$ of reduction) and $42 \mathrm{dptx}$ $(27.2 \pm 3.2 \%$ of reduction; Fig. $5 C$ ), indicating that TrkB signaling plays a role in the incorporation of adult-born PGCs. Such decrease in cell density became less evident at $3 \mathrm{mptx}(21.2 \pm$ $3.0 \%$ of reduction) and virtually disappeared at $6 \operatorname{mptx}(8.9 \pm$ $2.1 \%$ of reduction) and $9 \operatorname{mptx}(4.8 \pm 0.3 \%$ of reduction; Fig. $5 C)$. We then investigated the mechanisms responsible for this recovery of cell density in TrkB ${ }^{\text {lox/lox }}$-Cre mice at 6 and 9 mptx by pretreating mice with BrdU during the last 3 months before they were killed (Fig. 4G). At both analyzed time points, only a minority of adult-born PGCs was double positive for BrdU $(\beta \mathrm{gal}+/$ BrdU+) in control mice $(31.0 \pm 4.1 \%$ and $24.8 \pm 3.6 \%$ at 6 and 9 mptx, respectively), supporting the idea that neurons generated in older animals contribute to a lesser extent compared with earlier-born adult-generated PGCs to the total number of adultgenerated PGCs (Fig. 5D,E). Although the density of $\beta$ gal+ PGCs in TrkB ${ }^{\text {lox/lox }}$-Cre mice appeared similar to that of $\operatorname{TrkB}^{\mathrm{w} / \mathrm{w}}$ Cre mice at later analyzed time points (Fig. $5 C$ ), we noticed a significant increase in the corresponding number of newly generated PGCs that had been incorporated specifically during these stages $(\beta \mathrm{gal}+/ \mathrm{BrdU}+; 54.6 \pm 3.5 \%$ and $40.6 \pm 4.2 \%$ at 6 and 9 mptx, respectively; Fig. $5 D, E$ ). This increase appeared to be responsible for the apparent recovery of the total density of PGCs (Fig. 5C-E), suggesting that either the dependence of newborn PGCs on TrkB signaling (and TrkB ligands) declined with age or that the pre-existing network might favor the progressive incorporation of those specific classes of PGCs whose integration does not necessitate the activation of TrkB-FL.

To address this point, we analyzed the cellular composition of $\beta g a l+$ PGCs at $42 \mathrm{dptx}$, the time when $\operatorname{TrkB}^{\text {lox/lox}}$-Cre mice showed a clear deficit in cell density, and at $9 \mathrm{mptx}$, when this phenotype virtually disappeared (Fig. $5 C$ ). We quantified the relative proportions of $\mathrm{TH}$-positive $(\mathrm{TH}+), \mathrm{CB}$-positive $(\mathrm{CB}+)$, and $\mathrm{CR}$-positive $(\mathrm{CR}+)$ cells among $\beta$ gal + cells, representing the three main subgroups of PGCs integrating in the adult OB (Lledo et al., 2008). At $42 \mathrm{dptx}$, we observed a substantial reduction in the number of $\mathrm{TH}+$ and $\mathrm{CB}+$ cells in TrkB ${ }^{\text {lox/lox}}$-Cre mice compared with control mice (Fig. $5 F$ ), indicating that the loss of TrkB-FL preferentially impaired the incorporation of these cells but not that of CR + cells. Moreover, at 9 mptx the density of CR + cells in TrkB-deficient mice was considerably increased compared with controls, in sharp contrast to $\mathrm{TH}+$ cells, which were still markedly reduced in number (Fig. $5 F, G$ ).

We then assessed whether the reduced density of PGCs, and in particular of TH+ cells, observed in TrkB ${ }^{\text {lox/lox }}$-Cre mice was due to a failure of neuronal integration into the pre-existing network. We first injected Tx-induced TrkB ${ }^{\mathrm{w} / \mathrm{w}}-$ Cre and TrkB ${ }^{\text {lox/lox}}{ }_{-}$Cre mice with a control virus encoding DsRed and analyzed the mor- phological properties of PGCs at $21 \mathrm{dpi}$ (Fig. 5H). Contrary to neurons of the GCL (Fig. 4B-D), deletion of TrkB-FL produced a clear impairment in dendritic branching compared with TrkBexpressing newborn PGCs (Fig. 5I,K). This phenotype was rescued in neurons transduced with the TrkB ${ }^{\mathrm{WT}}$ retrovirus (Fig. $4 F$ ), and it was reproduced by injecting a $\operatorname{TrkB}^{\mathrm{FFF}}$-expressing virus (Fig. $5 I, K$ ), indicating that functional TrkB-FL is necessary for the development of dendrites in PGCs. Conspicuously, this dendritic impairment was also observed following injection of $\mathrm{TrkB}^{\text {Shc }}$-encoding virus in Tx-induced TrkB ${ }^{\text {lox/lox }}$-Cre mice (Fig. $5 I, K)$, suggesting that the main signaling pathway involved in dendritic growth was that activated by Shc. In contrast, the use of TrkB ${ }^{\text {PLC }}$-encoding virus resulted in a specific impairment of spine growth (Fig. $5 J$ ), similar to the phenotype observed in GCs. Together, our results indicate that adult-born PGCs, and predominantly $\mathrm{TH}+$ cells, depend on TrkB-FL signaling for their morphological maturation and stable incorporation into the $\mathrm{OB}$ network.

\section{Region- and layer-specific expression of BDNF in the adult $\mathrm{OB}$}

To gain insights into the pattern of BDNF expression in the adult $\mathrm{OB}$, we first assessed the distribution of its mRNA by in situ hybridization. We observed BDNF mRNA expression within the ML and GL (Fig. 6A), where principal neurons (mitral and tufted cells) and other glutamatergic short-axon cells normally reside (Shepherd, 2004). Indeed, high-magnification analysis within these two layers confirmed a significant expression of BDNF mRNA in Tbr2-positive cells, labeling mitral and tufted cells (Mizuguchi et al., 2012; Fig. 6A). Next, we investigated the pattern of BDNF protein expression by immunostaining. High levels of BDNF protein were observed within the ML and GL (Fig. 6B), according to BDNF mRNA distribution. Coimmunostaining for Tbr2 and BDNF confirmed the high expression of this neurotrophin in glutamatergic neurons within the ML, i.e., mitral cells (Mizuguchi et al., 2012), and in numerous cells bordering the GL, presumably tufted and other glutamatergic cells (Fig. $6 B-D$ ), indicating that local glutamatergic neurons may contribute to the local supply of BDNF.

Adult-generated olfactory bulb neurons are densely innervated by axonal fibers arising from glutamatergic projection neurons located in the $\mathrm{AON}$ and piriform cortex (PC; Whitman and Greer, 2007; Panzanelli et al., 2009; Deshpande et al., 2013). These corticofugal projections may therefore be an additional source of BDNF for neurons undergoing maturation. By examining these two cortical areas, we found high levels of BDNF mRNA (Fig. $6 E$ ) and protein expression (Fig. $6 F$ ). In addition, within the $\mathrm{OB}$, BDNF immunoreactivity was found in axonal fibers crossing the GCL (Fig. 6G), the area mostly innervated by corticofugal projections. Together, these results indicate the existence of a regionalized expression of BDNF in the adult $\mathrm{OB}$ and suggest that both long-distant projection neurons (AON and PC) and local glutamatergic neurons contribute to create a local gradient of BDNF, thus presumably regulating the maturation process of newly generated neurons.

\section{Failure of integration results in apoptosis of adult-born neurons at different levels of the $O B$ network}

To estimate the rate of neuronal loss following TrkB deletion in $\mathrm{TrkB}^{\text {lox/lox}}$-Cre mice, we performed an assay for active Casp3 and assessed the number of apoptotic cells. Analysis of mice at $42 \mathrm{dptx}$ revealed few positive cells per section in both $\operatorname{TrkB}^{\mathrm{w} / \mathrm{w}}-$ Cre and TrkB ${ }^{\text {lox/lox}}$-Cre mice (Fig. $7 A$ ), the majority of which were re- 


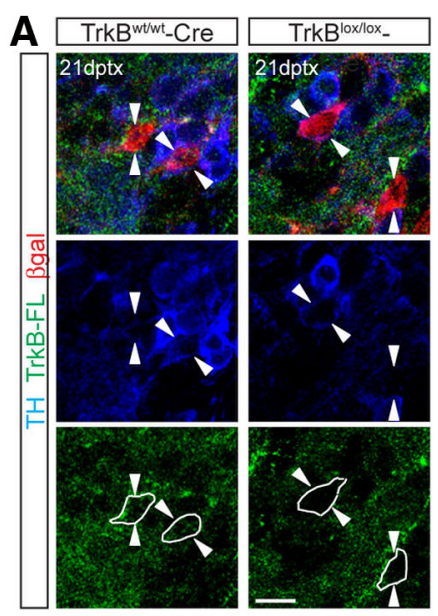

E

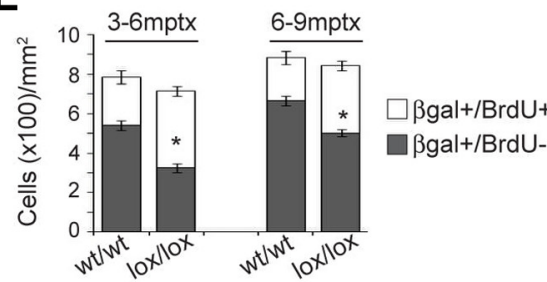

F

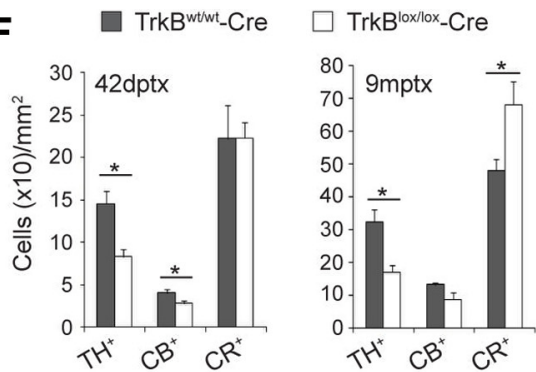

H

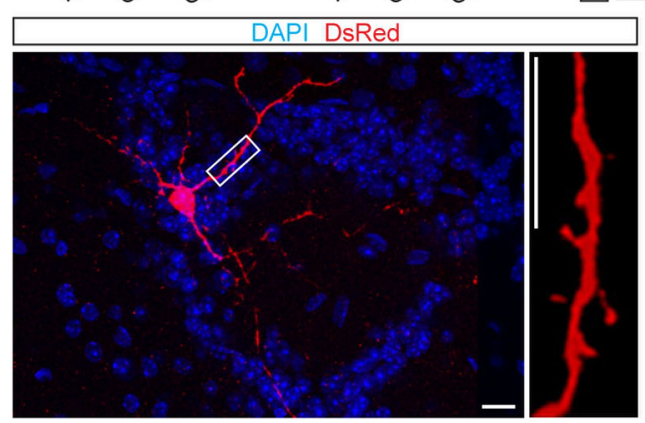

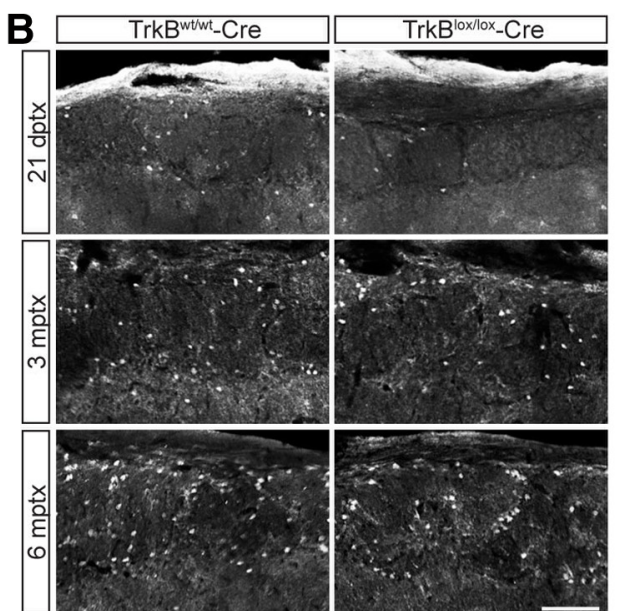

G
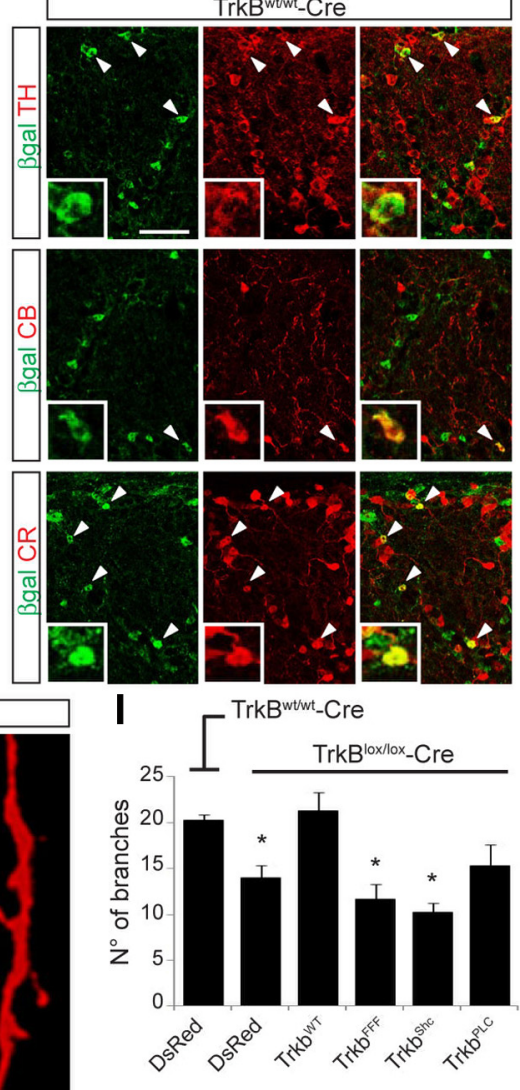

C

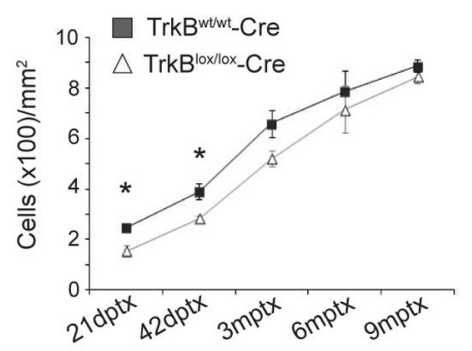

D
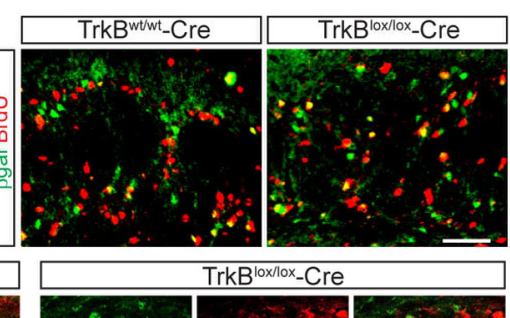

K
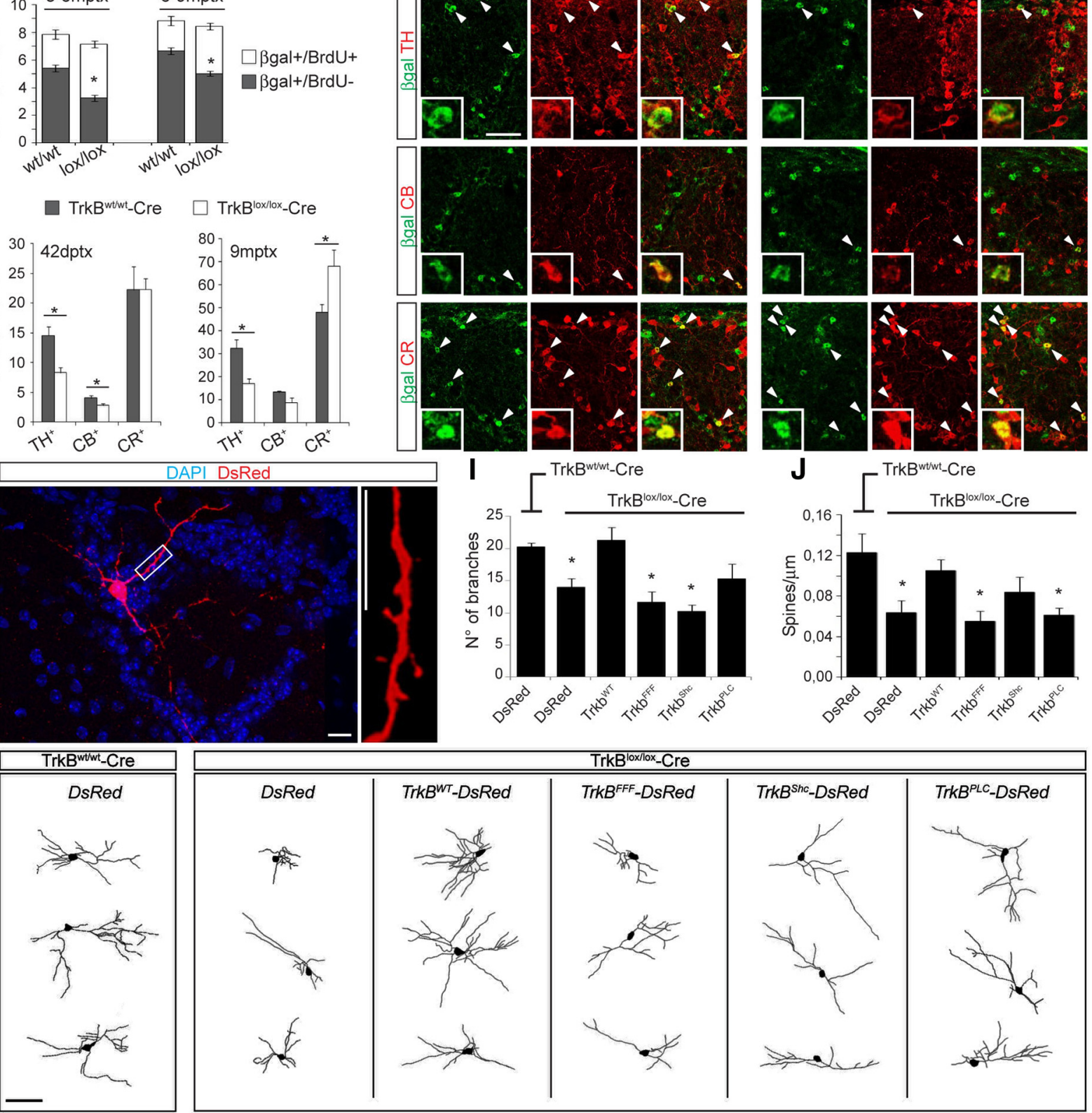

Figure 5. TrkB-FL deletion alters the morphological maturation of newly generated PGCs and their incorporation into the GL. $A$, Confocal pictures (single stacks) depicting the immunoreactivity for TrkB-FL in $\beta \mathrm{gal}+$ neurons at $21 \mathrm{dptx}$ in the $\mathrm{GL}$ of TrkB ${ }^{\mathrm{w} / \mathrm{w}}$-Cre and TrkB ${ }^{\text {lox/lox }}$-Cre mice. Arrowheads point to single $\beta$ gal + cells. For clarity, the cellular perimeter of $\beta$ gal + cells is indicated. Scale bar, $20 \mu \mathrm{m}$. B , Representative pictures showing the number of $\beta \mathrm{gal}+\mathrm{PGCs}$ in the GL of TrkB ${ }^{\mathrm{w} / \mathrm{w}}$-Cre and TrkB ${ }^{\text {lox/lox }}$-Cre mice at the indicated time points following (Figure legend continues.) 
porter negative, likely indicating basal levels apoptosis in preexisting neurons. Considering the change in shape of the $\mathrm{OB}$ and its relative substructures along the frontal-caudal axis, we quantified the number of Casp3 + cells, taking into account their distribution not only between the different layers of the OB (RMS$\mathrm{OB}, \mathrm{GCL}$, and GL), but also through the rostral-caudal axis (Fig. $7 B)$. We initially compared the density of Casp3 + cells that were reporter negative, which was very similar between the two experimental groups (Fig. 7C), thus suggesting that Tx-mediated Cre recombination did not produce non-cell-autonomous alterations in neuronal viability within the OB. Conversely, we observed a marked increase in the total number of newborn cells undergoing apoptosis $(\mathrm{Casp} 3+/ \beta \mathrm{gal}+)$ in $\mathrm{TrkB}^{\text {lox/lox}}$-Cre compared with control mice, particularly in sections corresponding to the medial portion of the $\mathrm{OB}$ (Fig. 7D). Interestingly, the increase in Casp3 $+/ \beta$ gal + cells appeared to be heterogeneous through layers and the rostro-caudal axis, following a pattern gradually shifting from the RMS-OB in caudal sections, to the GCL in medial sections, and toward the GL in more rostral sections (Fig. 7D), presumably reflecting regionalized gradients of BDNF present throughout the OB (Fig. 6).

$\mathrm{OB}$ glomeruli receive afferent projections from OSNs situated in the olfactory neuroepithelium (OE), which senses external odorant molecules and in turn signals to the olfactory cortex via the OB (Shepherd, 2004). Since the OE is one of the sites outside the CNS where adult neurogenesis persists (Leung et al., 2007), we analyzed this region for alterations that could potentially contribute to the observed phenotype in Tx-induced TrkB ${ }^{\text {lox/lox }}$-Cre. Forty-two days post-Tx treatment, we observed no visible recombination occurring in the $\mathrm{OE}$, either in progenitor cells [keratin5 $+(\mathrm{k} 5)$ ] or in OSNs [olfactory marker protein $(\mathrm{OMP}+)$; Fig. $7 E)$. Next, we assessed the functionality of the OE by recording electro-olfactograms in acute preparations after local stimulation of the nasal turbinates (Franceschini et al., 2009) with three different odorants (amylacetate, cineole, and acetophenone; Fig. $7 F, G)$. Notably, the voltage changes induced by the odorants were comparable between $\operatorname{TrkB}^{\mathrm{w} / \mathrm{w}}$-Cre and $\operatorname{TrkB}{ }^{\text {lox/lox}}-C r e$ mice, with no significant alteration detected (Fig. $7 H$ ), suggesting that the impairments in morphological maturation and survival of adult-born PGCs observed in TrkB ${ }^{\text {lox/lox }}$-Cre mice was presumably not due to changes in OSNs activity. Altogether, our data indicate a cell-autonomous role for TrkB signaling in the integration and survival of adult-born PGCs.

\section{Discussion}

Turnover of adult-generated neurons has been proposed to play a role in the experience-dependent plasticity of the $\mathrm{OB}$,

\section{$\leftarrow$}

(Figure legend continued.) Tx treatment. Scale bar, $100 \mu \mathrm{m}$. C, Absolute density of $\beta \mathrm{gal}+$ PGCs quantified starting from $21 \mathrm{dptx}$ to $9 \mathrm{mptx}\left(n=3\right.$ mice). ${ }^{*} p<0.05$. D, Distribution of $\beta \mathrm{gal}+/ \mathrm{BrdU}-$ and double-positive PGCs in the GL at $6 \mathrm{mptx}$. E, Proportion of BrdU + and $\mathrm{BrdU}-\mathrm{PGC}$ samong the total number of $\beta$ gal $+\mathrm{PGC}$ at 6 and $9 \mathrm{mptx}\left(n=3\right.$ mice). ${ }^{*} p<0.05$. Scale bar, $50 \mu \mathrm{m}$. $F$, Density of TH,$+ C B+$, and CR + cells among $\beta$ gal + cells in the $G \mathrm{~L}$ at 42 dptx and $9 \mathrm{mptx}$ ( $n=3$ mice). ${ }^{*} p<0.05$. G, Representative pictures obtained at $9 \mathrm{mptx}$ showing the relative changes in density of $\beta \mathrm{gal}+/ \mathrm{TH}+, \beta \mathrm{gal}+/ \mathrm{CB}+$, and $\beta \mathrm{gal}+/ \mathrm{CR}+$

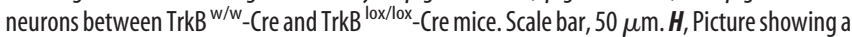
newly generated $\mathrm{PGC}$ and relative spines at $21 \mathrm{dpi}$ with a DsRed-encoding retrovirus. Scale bar, $10 \mu \mathrm{m}$. I, Branch number of neurons transduced with the indicated viral vectors at $21 \mathrm{dpi}$ in Tx-treated TrkB ${ }^{w / w}$-Cre or TrkB ${ }^{\text {lox/lox }}$-Cre mice $\left(n=10-15\right.$ neurons/condition). ${ }^{*} p<0.05$.J, Spine density quantified along first- and second-order dendrites of the same neurons analyzed in $\boldsymbol{I}(n=10-15$ neurons/condition, one to three dendritic segments analyzed per neuron). ${ }^{*} p<0.05$. $\boldsymbol{K}$, Reconstruction of representative PGCs at $21 \mathrm{~d}$ following transduction with the indicated viral constructs in Tx-treated TrkB ${ }^{\mathrm{w} / \mathrm{w}_{-}}$-Cre or TrkB ${ }^{\text {lox/lox }}$-Cre mice. Scale bar, $30 \mu \mathrm{m}$. particularly by contributing to discrimination and memory retention of odorant molecules (Mouret et al., 2009; Alonso et al., 2012). Such proposed functions are likely related to the constant replacement of pre-existing neurons with newcomers, a mechanism possibly providing unique degrees of network plasticity, as well as to the permanent integration of selected neurons that are characterized by high rates of synapse formation and remodeling (Mizrahi, 2007; Livneh et al., 2009), and thus may allow for the consolidation of specifically active information channels. In this study, we present clear evidence that the morphological integration and stable incorporation of new PGCs into the network is regulated by TrkB signaling. Newly generated PGCs lacking TrkB-FL displayed a marked reduction in the complexity of their dendritic tree and exhibited fewer spines than control neurons. We identified $\mathrm{Shc} / \mathrm{PI} 3 \mathrm{~K}$ as the signaling cascade responsible for PGCs' dendritic development, while TrkB signaling via PLC $\gamma$ was required for spine formation. The morphological and synaptic impairments observed in TrkB-deficient neurons were precisely coincident with the time of their functional integration (Carleton et al., 2003; Kelsch et al., 2008), reflecting the principle that neurotrophic factors play a key role during the first steps of integration into the pre-existing circuitry (Bergami and Berninger, 2012). These morphological symptoms observed following deletion of TrkB in PGCs, and in particular the reduction in spine growth, were likely to be responsible for a failure in synaptic integration and the consequent reduced survival.

The peculiar pattern of apoptosis observed in TrkB ${ }^{\text {lox/lox }}$-Cre mice, i.e., the differences between the more central and deep regions of the $\mathrm{OB}$ compared with rostral and more superficial ones, is particularly intriguing. This pattern could reflect the existence of a gradient of BDNF along the rostro-caudal axis of the OB (Bath et al., 2008), resulting in regional differences in the availability of the neurotrophin. We showed that both local (mitral and tufted cells) and long-distance projection neurons (AON and $\mathrm{PC}$ ) are among the main sources of BDNF for the OB. However, synapses formed by centrifugal projections, whether transient or stable, are believed to be established onto adult-born neurons before these receive inputs by local mitral and tufted cells (Whitman and Greer, 2007; Panzanelli et al., 2009). This temporal and spatial pattern of connectivity correlates well with the pattern of cell death observed in $\operatorname{TrkB}{ }^{\text {lox/lox}}$-Cre mice (Fig. $7 D$ ), with neurons found in apoptosis already from their first steps of integration into the GCL, a region that is densely innervated by corticofugal projections (Fig. 6G). These results suggest that TrkB signaling is already required from this early stage of integration, when new neurons begin to receive their first synaptic inputs (Belluzzi et al., 2003; Carleton et al., 2003; Panzanelli et al., 2009; Deshpande et al., 2013). Interestingly, $\mathrm{TH}+$ newborn neurons appeared particularly affected by the lack of TrkB, as demonstrated by their substantial depletion from the GL of TrkB ${ }^{\text {lox/lox }}$ Cre mice even at late stages following Tx induction. Given the proposed unique function of $\mathrm{TH}+$ neurons among other types of PGCs in modulating interglomerular circuits and mitral/tufted cell excitability (Kiyokage et al., 2010), it is intriguing to speculate that a long-lasting impairment in the survival of adult-generated dopaminergic PGCs may alter the local network and thus odor information processing (Alonso et al., 2012).

By means of genetic fate mapping (Ninkovic et al., 2007; Imayoshi et al., 2008) and in vivo two-photon microscopy (Adam and Mizrahi, 2011), recent studies described a scenario in which new PGCs become gradually added to pre-existing cells, thus 

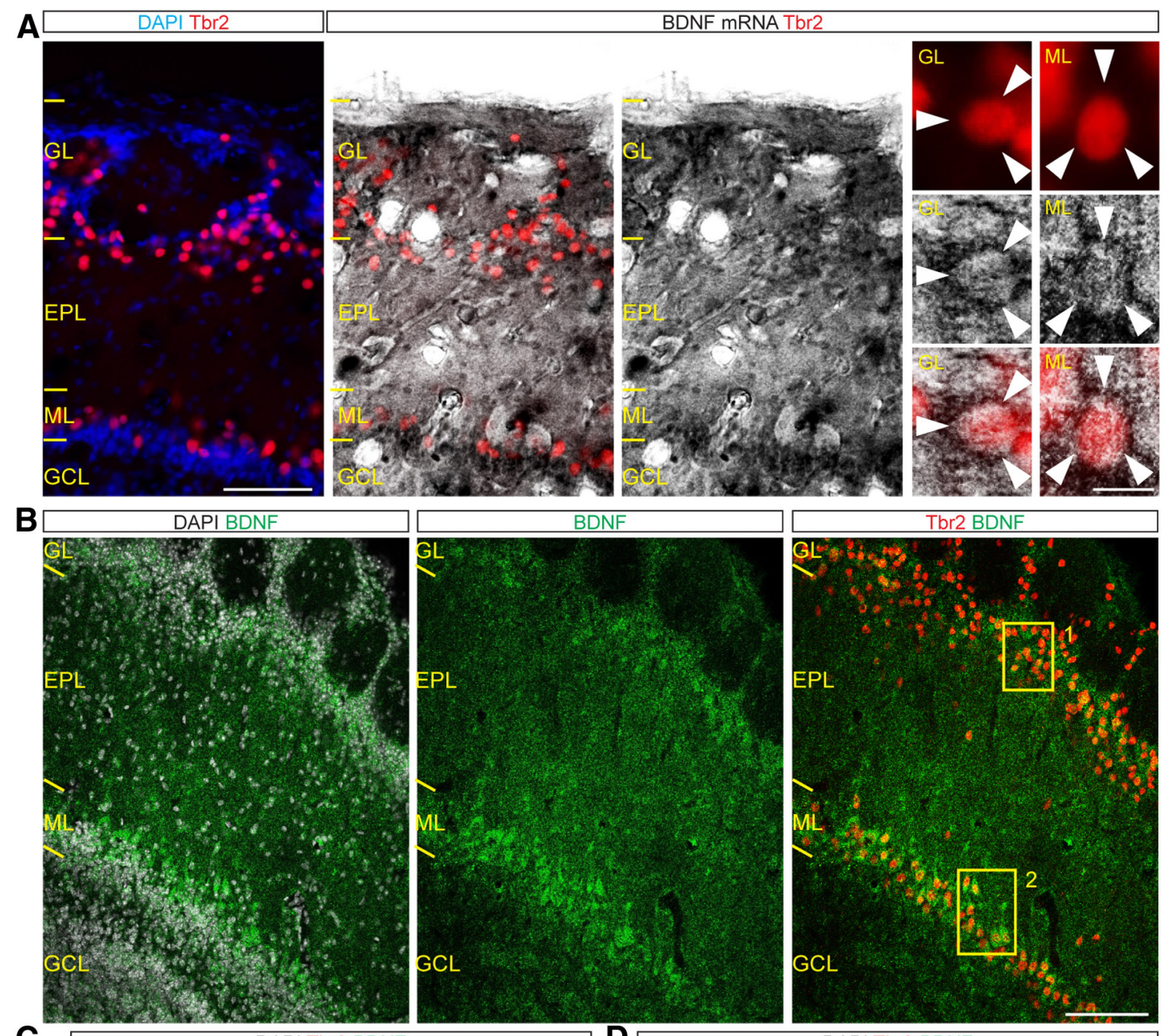

C

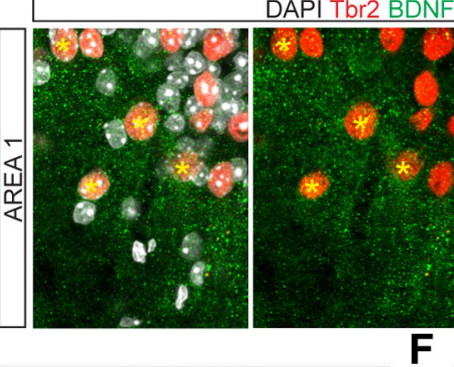

D

DAPI Tbr2 BDNF

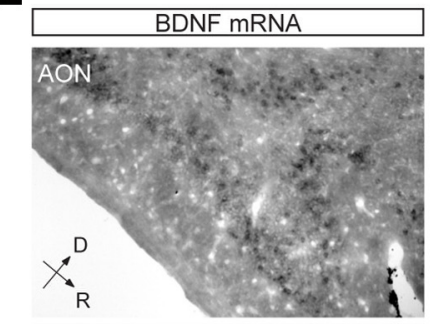

$\mathbf{F}$
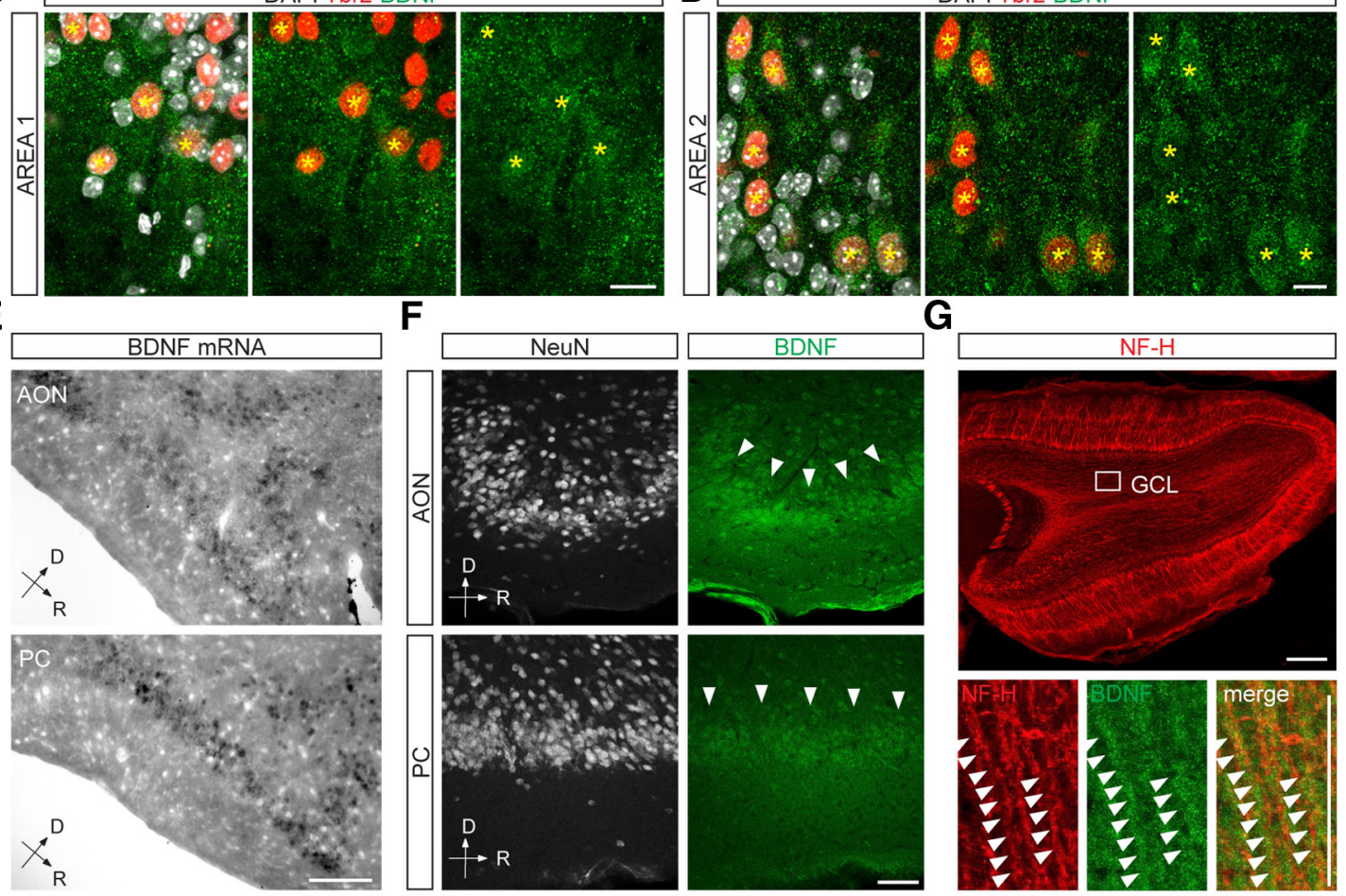

Figure 6. Regionalized expression of BDNF in the OB. A, In situ hybridization showing the enrichment in BDNF mRNA within the ML and GL. Glutamatergic neurons were revealed with anti-Tbr2 immunostaining. High magnification images on the right show BDNF mRNA in individual Tbr2+ neurons located in the GL and ML. Scale bars: left, $100 \mu \mathrm{m}$; right, $15 \mu \mathrm{m} . \boldsymbol{B}$, Representative micrographs showing the distribution of BDNF immunoreactivity within the superficial layers of the OB. BDNF protein was mostly concentrated in the ML and GL and was (Figure legend continues.) 

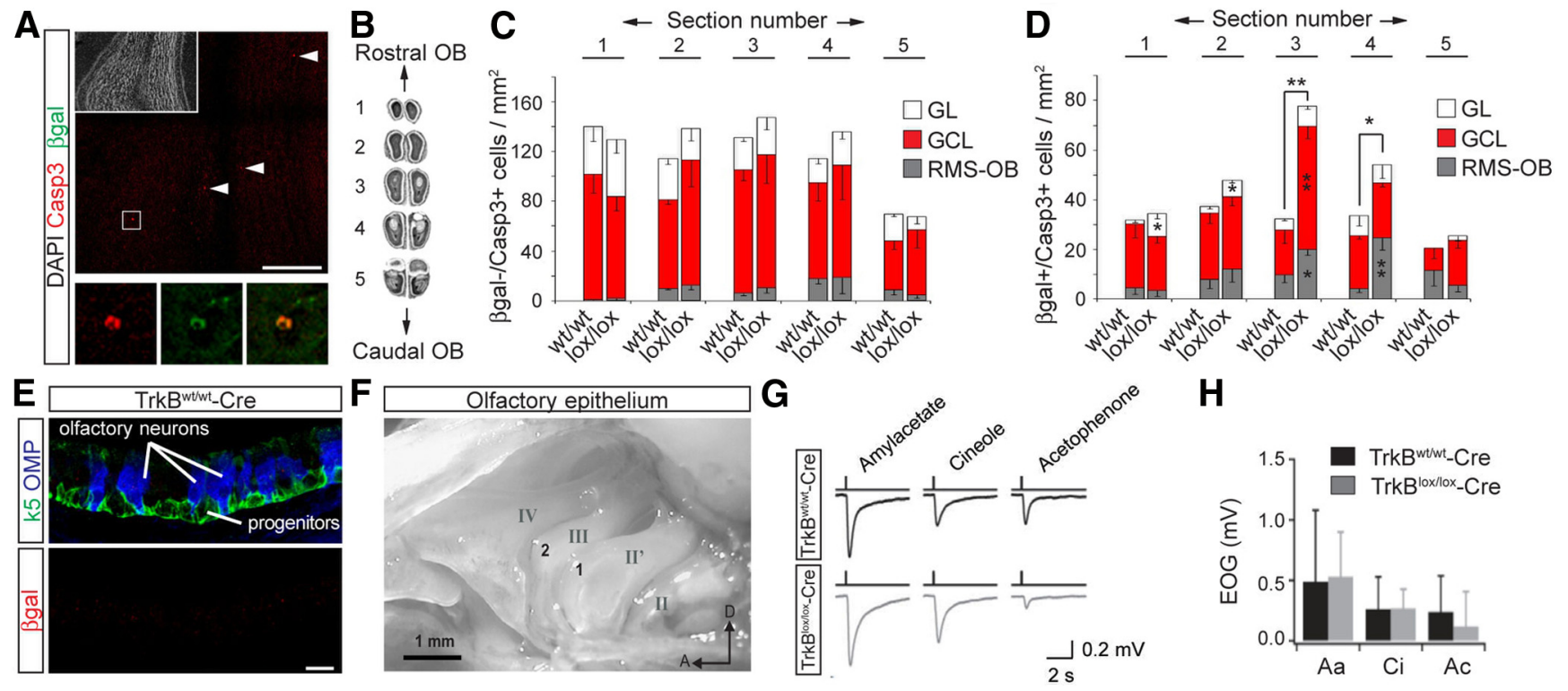

Figure 7. Conditional deletion of TrkB-FL in adult-born neurons leads to a cell-autonomous impairment of neuronal survival. $A$, Representative section of the $0 B$ (see DAPI staining in the inset) immunostained for active Casp3 and showing the presence of Casp3 $+/ \beta$ gal - cells (arrowheads) in Tx-treated TrkB ${ }^{w / w}$-Cre mice. Scale bar, $100 \mu \mathrm{m}$. Bottom, A magnification of a $\beta$ gal $+/$ Casp3 + cell (boxed area). Scale bar, $200 \mu \mathrm{m}$. B, Schematic illustrating the sectioning of the OB used for quantifications in relation to the rostro- caudal axis. Sections were divided into five groups along the axis. C, Density of $\beta \mathrm{gal}-/$ Casp3 + cells along the rostro- caudal axis and between the different layers of the OB (RMS-OB, GCL, and GL) in Tx-treated TrkB ${ }^{\mathrm{w} /{ }^{w}}$-Cre and TrkB ${ }^{\text {lox/lox }}$-Cre mice at $42 \mathrm{dptx}$ ( $n=3$ mice). D, Density of $\beta$ gal $+/$ Casp3 + cells quantified as in $C\left(n=3\right.$ mice). ${ }^{*} p<0.05$; ${ }^{* *} p<0.01$. E, Representative confocal picture showing a portion of the 0 E at $42 \mathrm{dptx}$ in

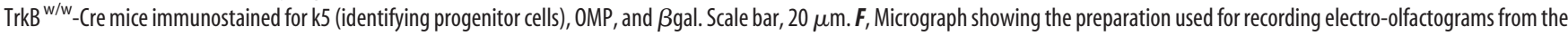
OE. Roman numbers indicate individual turbinates; the locations in which recordings were usually performed (1,2) are shown. D, Dorsal; $A$, anterior. $\mathbf{G}$, Representative electro-olfactogram recordings obtained from the $0 \mathrm{E}$ of TrkB ${ }^{\mathrm{w} / w_{-}}$-Cre and TrkB ${ }^{\text {lox/lox}}$-Cre mice at $42 \mathrm{dptx}$ in response to $100 \mathrm{~ms}$ pulses (top traces) of amylacetate, cineole, and acetophenone. $\boldsymbol{H}$, Histogram showing the average voltage amplitude recorded following stimulation with the three individual odorant molecules ( $n=3-5$ mice).

producing an overall increase (per month) of $2-4 \%$ of the total number of PGCs (Lagace et al., 2007; Adam and Mizrahi, 2011). The rate of neuronal incorporation, as well as synapse formation in adult-born neurons, is precisely refined by odor stimulation/ deprivation (Yamaguchi and Mori, 2005; Livneh et al., 2009; Sawada et al., 2011) and therefore responds to olfactory sensory activity. It may therefore be reasonable to assume that activitydependent secreted factors, such as BDNF (Poo, 2001), could play a critical role in this neuronal recruitment. Supporting this hypothesis, BDNF signaling has been implicated in the generation, migration, and survival of new neurons in the adult SEZ/ RMS/OB (Young et al., 2007; Bath et al., 2008; Galvão et al., 2008; Snapyan et al., 2009). However, experiments have yielded conflicting results, particularly with regard to the role of BDNF in regulating survival of newborn neurons (Bath et al., 2008; Galvão et al., 2008). Here, we found no evidence that proliferation directly depends on the activation of TrkB-FL in stem and progenitor cells. Instead, rather than TrkB-FL, cells in the SEZ express TrkB-T and the low-affinity neurotrophin receptor $\mathrm{p} 75^{\mathrm{NTR}}$ (Young et al., 2007; Galvão et al., 2008), suggesting that the spa-

$\leftarrow$

(Figure legend continued.) found to colocalize with Tbr2+ neurons, labeling mitral and tufted cells. Scale bar, $100 \mu \mathrm{m}$. C, High magnification image of area 1 boxed in $\boldsymbol{B}$, illustrating a portion of the GL and BDNF expression in Tbr2 + neurons (yellow asterisks). Scale bar, $15 \mu \mathrm{m}$. $\boldsymbol{D}$, High magnification image of area 2 boxed in $\boldsymbol{B}$, illustrating a portion of the ML and BDNF expression Tbr2+ mitral cells (yellow asterisks). Scale bar, $15 \mu \mathrm{m}$. $\boldsymbol{E}$, In situ hybridization showing abundant BDNF mRNA expression in the AON and PC. Scale bar, $100 \mu \mathrm{m}$. $\boldsymbol{F}$, Pictures showing BDNF immunoreactivity in neurons of the AON and PC. Scale bar, $50 \mu \mathrm{m}$. G, Overview of the $\mathrm{OB}$ showing the immunoreactivity for neurofilament-H (NF-H), which, in addition to mitral cells, labels centrifugal cortical fibers innervating the GCL. Bottom panels show the presence of BDNF immunoreactivity in NF- H + fibers crossing the GCL. Scale bars: bottom, $200 \mu \mathrm{m}$; top, $50 \mu \mathrm{m}$. D, Dorsal; R, rostral. tiotemporal expression of BDNF receptors along the SVZ/ RMS/OB path may serve for distinct functions. Notably, experiments conducted on postnatal TrkB knock-out cells transplanted into the SEZ of wild-type adult mice led to the conclusion that BDNF does not cell-autonomously control neuronal migration via TrkB (Galvão et al., 2008), a finding that we confirmed by deleting TrkB-FL specifically in adult-born neurons. Additional insights about the BDNF effects on adult neurogenesis were provided using TrkB heterozygous and BDNF mutant mice in which BDNF activity-dependent secretion is impaired (Bath et al., 2008). In these mice, the overall number of newborn GCs was shown to be particularly affected (Bath et al., 2008). Opposite to this study, however, we detected no alterations in the number of GCs up to 9 months after conditional deletion of TrkB-FL despite clear impairment in spine growth, suggesting that a general reduction of BDNF protein or secretion in the SEZ/RMS/OB system might impair either migration or survival of newborn neurons in a non-cell-autonomous manner (Snapyan et al., 2009).

The time window when we noticed the morphological impairments both in GCs and PGCs caused by TrkB deletion coincides with the critical period characterized by an enhanced propensity for synaptic plasticity in newly generated neurons (Nissant et al., 2009), a feature that could be critically modulated by BDNF secretion at the synaptic level. In this respect, it is remarkable that the local availability of BDNF seems to differ significantly between the layers of the $O B$, with the ML and GL particularly enriched in BDNF protein levels. This regionalized pattern of BDNF expression correlates well with the reduced spine density observed both in GCs and PGCs following TrkB-FL deletion, suggesting that BDNF/ TrkB signaling plays a role during synapse formation between 
newborn neurons and mitral or tufted cells. Moreover, the high immunoreactivity for BDNF detected in the GL, likely revealing not only BDNF expression in local neurons but also in OSN axonal projections (Clevenger et al., 2008; Feron et al., 2008), indicates that newborn PGCs, and predominantly $\mathrm{TH}+$ cells, are particularly dependent on TrkB signaling for their morphological maturation (extension of dendrites) and synaptic integration (spine growth). During the course of their maturation, BDNF may represent a limiting factor for the survival of these neurons and for their stable incorporation into the network, suggesting the existence of active mechanisms of competition between cohorts of newborn neurons as proposed for the DG (Tashiro et al., 2006; Bergami et al., 2008).

The identification of a role for TrkB in contributing to the turnover of PGCs mirrors the diverse modes of incorporation of adult-generated neurons in the GCL and GL. Strikingly, the missing fraction of $\mathrm{TH}+$ cells generated at younger stages following TrkB-FL deletion was never recovered, thus creating a permanent imbalance in the cellular composition of the adult GL. Our data suggest that layer-specific cues such as BDNF, the expression of which could be modulated by network activity, are required for the integration of specific subsets of adult-born OB neurons.

\section{References}

Adam Y, Mizrahi A (2011) Long-term imaging reveals dynamic changes in the neuronal composition of the glomerular layer. J Neurosci 31: 7967-7973. CrossRef Medline

Alonso M, Lepousez G, Sebastien W, Bardy C, Gabellec MM, Torquet N, Lledo PM (2012) Activation of adult-born neurons facilitates learning and memory. Nat Neurosci 15:897-904. CrossRef Medline

Bath KG, Mandairon N, Jing D, Rajagopal R, Kapoor R, Chen ZY, Khan T, Proenca CC, Kraemer R, Cleland TA, Hempstead BL, Chao MV, Lee FS (2008) Variant brain-derived neurotrophic factor (Val66Met) alters adult olfactory bulb neurogenesis and spontaneous olfactory discrimination. J Neurosci 28:2383-2393. CrossRef Medline

Belluzzi O, Benedusi M, Ackman J, LoTurco JJ (2003) Electrophysiological differentiation of new neurons in the olfactory bulb. J Neurosci 23:1041110418. Medline

Bergami M, Berninger B (2012) A fight for survival: the challenges faced by a newborn neuron integrating in the adult hippocampus. Dev Neurobiol 72:1016-1031. CrossRef Medline

Bergami M, Rimondini R, Santi S, Blum R, Götz M, Canossa M (2008) Deletion of TrkB in adult progenitors alters newborn neuron integration into hippocampal circuits and increases anxiety-like behavior. Proc Natl Acad Sci U S A 105:15570-15575. CrossRef Medline

Brill MS, Ninkovic J, Winpenny E, Hodge RD, Ozen I, Yang R, Lepier A, Gascón S, Erdelyi F, Szabo G, Parras C, Guillemot F, Frotscher M, Berninger B, Hevner RF, Raineteau O, Götz M (2009) Adult generation of glutamatergic olfactory bulb interneurons. Nat Neurosci 12:15241533. CrossRef Medline

Carleton A, Petreanu LT, Lansford R, Alvarez-Buylla A, Lledo PM (2003) Becoming a new neuron in the adult olfactory bulb. Nat Neurosci 6:507518. CrossRef Medline

Clevenger AC, Salcedo E, Jones KR, Restrepo D (2008) BDNF promotermediated beta-galactosidase expression in the olfactory epithelium and bulb. Chem Senses 33:531-539. CrossRef Medline

Deshpande A, Bergami M, Ghanem A, Conzelmann KK, Lepier A, Götz M, Berninger B (2013) Retrograde monosynaptic tracing reveals the temporal evolution of inputs onto new neurons in the adult dentate gyrus and olfactory bulb. Proc Natl Acad Sci U S A 110:E1152-E1161. CrossRef Medline

Feron F, Bianco J, Ferguson I, Mackay-Sim A (2008) Neurotrophin expression in the adult olfactory epithelium. Brain Res 1196:13-21. CrossRef Medline

Franceschini V, Bettini S, Pifferi S, Rosellini A, Menini A, Saccardi R, Ognio E, Jeffery R, Poulsom R, Revoltella RP (2009) Human cord blood CD133+ stem cells transplanted to nod-scid mice provide conditions for regener- ation of olfactory neuroepithelium after permanent damage induced by dichlobenil. Stem Cells 27:825-835. CrossRef Medline

Galvão RP, Garcia-Verdugo JM, Alvarez-Buylla A (2008) Brain-derived neurotrophic factor signaling does not stimulate subventricular zone neurogenesis in adult mice and rats. J Neurosci 28:13368-13383. CrossRef Medline

Hofer M, Pagliusi SR, Hohn A, Leibrock J, Barde YA (1990) Regional distribution of brain-derived neurotrophic factor mRNA in the adult mouse brain. EMBO J 9:2459-2464. Medline

Imayoshi I, Sakamoto M, Ohtsuka T, Takao K, Miyakawa T, Yamaguchi M, Mori K, Ikeda T, Itohara S, Kageyama R (2008) Roles of continuous neurogenesis in the structural and functional integrity of the adult forebrain. Nat Neurosci 11:1153-1161. CrossRef Medline

Kelsch W, Lin CW, Lois C (2008) Sequential development of synapses in dendritic domains during adult neurogenesis. Proc Natl Acad Sci U S A 105:16803-16808. CrossRef Medline

Kiyokage E, Pan YZ, Shao Z, Kobayashi K, Szabo G, Yanagawa Y, Obata K, Okano H, Toida K, Puche AC, Shipley MT (2010) Molecular identity of periglomerular and short axon cells. J Neurosci 30:1185-1196. CrossRef Medline

Klein R, Parada LF, Coulier F, Barbacid M (1989) trkB, a novel tyrosine protein kinase receptor expressed during mouse neural development. EMBO J 8:3701-3709. Medline

Klein R, Conway D, Parada LF, Barbacid M (1990) The trkB tyrosine protein kinase gene codes for a second neurogenic receptor that lacks the catalytic kinase domain. Cell 61:647-656. CrossRef Medline

Lagace DC, Whitman MC, Noonan MA, Ables JL, DeCarolis NA, Arguello AA, Donovan MH, Fischer SJ, Farnbauch LA, Beech RD, DiLeone RJ, Greer CA, Mandyam CD, Eisch AJ (2007) Dynamic contribution of nestin-expressing stem cells to adult neurogenesis. J Neurosci 27: 12623-12629. CrossRef Medline

Leung CT, Coulombe PA, Reed RR (2007) Contribution of olfactory neural stem cells to tissue maintenance and regeneration. Nat Neurosci 10:720-726. CrossRef Medline

Livneh Y, Feinstein N, Klein M, Mizrahi A (2009) Sensory input enhances synaptogenesis of adult-born neurons. J Neurosci 29:86-97. CrossRef Medline

Lledo PM, Alonso M, Grubb MS (2006) Adult neurogenesis and functional plasticity in neuronal circuits. Nat Rev Neurosci 7:179-193. CrossRef Medline

Lledo PM, Merkle FT, Alvarez-Buylla A (2008) Origin and function of olfactory bulb interneuron diversity. Trends Neurosci 31:392-400. CrossRef Medline

Lois C, García-Verdugo JM, Alvarez-Buylla A (1996) Chain migration of neuronal precursors. Science 271:978-981. CrossRef Medline

Merkle FT, Mirzadeh Z, Alvarez-Buylla A (2007) Mosaic organization of neural stem cells in the adult brain. Science 317:381-384. CrossRef Medline

Minichiello L (2009) TrkB signalling pathways in LTP and learning. Nat Rev Neurosci 10:850-860. CrossRef Medline

Minichiello L, Korte M, Wolfer D, Kühn R, Unsicker K, Cestari V, RossiArnaud C, Lipp HP, Bonhoeffer T, Klein R (1999) Essential role for TrkB receptors in hippocampus-mediated learning. Neuron 24:401-414. CrossRef Medline

Mizrahi A (2007) Dendritic development and plasticity of adult-born neurons in the mouse olfactory bulb. Nat Neurosci 10:444-452. CrossRef Medline

Mizuguchi R, Naritsuka H, Mori K, Mao CA, Klein WH, Yoshihara Y (2012) Tbr2 deficiency in mitral and tufted cells disrupts excitatory-inhibitory balance of neural circuitry in the mouse olfactory bulb. J Neurosci 32: 8831-8844. CrossRef Medline

Mori T, Tanaka K, Buffo A, Wurst W, Kühn R, Götz M (2006) Inducible gene deletion in astroglia and radial glia-a valuable tool for functional and lineage analysis. Glia 54:21-34. CrossRef Medline

Mouret A, Lepousez G, Gras J, Gabellec MM, Lledo PM (2009) Turnover of newborn olfactory bulb neurons optimizes olfaction. J Neurosci 29: 12302-12314. CrossRef Medline

Ninkovic J, Mori T, Götz M (2007) Distinct modes of neuron addition in adult mouse neurogenesis. J Neurosci 27:10906-10911. CrossRef Medline

Nissant A, Bardy C, Katagiri H, Murray K, Lledo PM (2009) Adult neuro- 
genesis promotes synaptic plasticity in the olfactory bulb. Nat Neurosci 12:728-730. CrossRef Medline

Panzanelli P, Bardy C, Nissant A, Pallotto M, Sassoè-Pognetto M, Lledo PM, Fritschy JM (2009) Early synapse formation in developing interneurons of the adult olfactory bulb. J Neurosci 29:15039-15052. CrossRef Medline

Poo MM (2001) Neurotrophins as synaptic modulators. Nat Rev Neurosci 2:24-32. CrossRef Medline

Rose CR, Blum R, Pichler B, Lepier A, Kafitz KW, Konnerth A (2003) Truncated TrkB-T1 mediates neurotrophin-evoked calcium signalling in glia cells. Nature 426:74-78. CrossRef Medline

Sawada M, Kaneko N, Inada H, Wake H, Kato Y, Yanagawa Y, Kobayashi K, Nemoto T, Nabekura J, Sawamoto K (2011) Sensory input regulates spatial and subtype-specific patterns of neuronal turnover in the adult olfactory bulb. J Neurosci 31:11587-11596. CrossRef Medline

Shepherd GM (2004) The synaptic organization of the brain, Ed 5. Oxford: Oxford UP.

Sholl DA (1953) Dendritic organization in the neurons of the visual and motor cortices of the cat. J Anat 87:387-406. Medline

Snapyan M, Lemasson M, Brill MS, Blais M, Massouh M, Ninkovic J, Gravel C, Berthod F, Götz M, Barker PA, Parent A, Saghatelyan A (2009) Vasculature guides migrating neuronal precursors in the adult mammalian forebrain via brain-derived neurotrophic factor signaling. J Neurosci 29: 4172-4188. CrossRef Medline

Soriano P (1999) Generalized lacZ expression with the ROSA26 Cre reporter strain. Nat Genet 21:70-71. CrossRef Medline

Tashiro A, Sandler VM, Toni N, Zhao C, Gage FH (2006) NMDA-receptormediated, cell-specific integration of new neurons in adult dentate gyrus. Nature 442:929-933. CrossRef Medline

van Praag H, Schinder AF, Christie BR, Toni N, Palmer TD, Gage FH (2002) Functional neurogenesis in the adult hippocampus. Nature 415: 1030-1034. CrossRef Medline

Whitman MC, Greer CA (2007) Synaptic integration of adult-generated olfactory bulb granule cells: basal axodendritic centrifugal input precedes apical dendrodendritic local circuits. J Neurosci 27:9951-9961. CrossRef Medline

Yamaguchi M, Mori K (2005) Critical period for sensory experiencedependent survival of newly generated granule cells in the adult mouse olfactory bulb. Proc Natl Acad Sci U S A 102:9697-9702. CrossRef Medline

Young KM, Merson TD, Sotthibundhu A, Coulson EJ, Bartlett PF (2007) p75 neurotrophin receptor expression defines a population of BDNFresponsive neurogenic precursor cells. J Neurosci 27:5146-5155. CrossRef Medline 